\title{
Global Ultra-Low-Frequency Geomagnetic Pulsations Associated with the March 24, 1991 Geomagnetic Storm
}

\author{
Nan-Wei Chen ${ }^{1, *}$ and Jann-Yenq Liu ${ }^{2}$ \\ ${ }^{1}$ Department of Electrical Engineering, National Central University, Chung-Li 32054, Taiwan, ROC \\ ${ }^{2}$ Institute of Space Science and Center for Space and Remote Sensing Research, National Central University, Chung-Li 32054, \\ Taiwan, $R O C$
}

Received 21 June 2006, accepted 26 June 2007

\begin{abstract}
On 24 March 1991, global ultra-low-frequency (ULF) pulsations $(1.1-3.3 \mathrm{mHz})$ observed in the magnetosphere as well as on the ground were studied via analyzing magnetic field data obtained from a global network, comprising ground-based observatories and geosynchronous satellites. In the magnetosphere, the compressional and transverse components of the magnetic fields recorded at two satellites, GOES 6 and GOES 7, showed dominant fluctuations when they were in the vicinity of the noon sector, whereas the transverse fluctuations became dominant when they were at the dawn side. Similarly, on the ground, the $\mathrm{H}$ and $\mathrm{D}$ components had major fluctuations along with an increase in amplitude from low to high geomagnetic latitudes. In addition, the amplitude of the ULF pulsation was enhanced at the dawn and dusk sides. The geomagnetic pulsations propagated anti-sunward and were of counterclockwise and clockwise elliptical polarizations at the dawn and dusk sides respectively. The counterclockwise elliptical polarization reversed to a clockwise elliptical polarization at geomagnetic local noon and linear polarization was observed during the reversal. It appears that the analysis of the global network data not only provided us with a study of the characteristics of the waves in the magnetosphere and on the ground but also provided us with correlations between the geosynchronous and ground observations, which should be essential to the determination of possible mechanisms of this storm-related wave event.
\end{abstract}

Key words: ULF pulsations, Solar wind-magnetosphere interactions, MHD waves and instabilities

Citation: Chen, N. W. and J. Y. Liu, 2008: Global ultra-low-frequency geomagnetic pulsations associated with the March 24, 1991 geomagnetic storm. Terr. Atmos. Ocean. Sci., 19, 291-308, doi: 10.3319/TAO.2008.19.3.291(AA)

\section{INTRODUCTION}

Scientists often regard ultra-low-frequency (ULF) geomagnetic pulsations as variations of the geomagnetic field caused by the propagation of magnetohydrodynamic (MHD) waves in the magnetosphere. These long-period pulsations are typically observed near auroral regions during the recovery phases of magnetic storms and substorms (e.g., Walker et al. 1992; Dunlop et al. 1994; McHarg et al. 1995). It has been well established that MHD waves result in compressional (poloidal) and transverse (toroidal) pulsations when they travel along and across field lines respectively (Westphal and Jacobs 1962; Alfven and Falthammar 1963). Regarding the sources of the MHD waves, it is known the sources of MHD waves mainly fall into two categories, viz.

\footnotetext{
* Corresponding author

E-mail:nwchen@ee.ncu.edu.tw
}

outside or inside the magnetosphere. For interpreting observations of the storm-related pulsations presented later in this paper, the characteristics of the waves excited outside the magnetosphere are briefly described. A general discussion of the two sources is provided in (McPherron 2002) and the references therein. Generally speaking, the sources inside the magnetosphere, e.g., the plasma kinetic or MHD type instabilities (e.g., Cheng and Lin 1987; Cheng and Qian 1994), and the sources outside the magnetosphere, e.g., the solar wind (Barnes 1983; Samson et al. 1991; Kepko et al. 2002), the bowshock (Russell 1985; Spreiter and Stahara 1985), and the magnetopause (Southwood and Kivelson 1989; Kivelson and Southwood 1991), can excite ULF waves. The ULF waves excited outside the magnetosphere can penetrate the magnetosphere through the magnetopause. These penetrated ULF waves are transformed and amplified 
in the magnetosphere. Below, the two processes related to the transformation of the wave energy are described briefly.

The first process is termed "field line resonance (FLR)" (Chen and Hasegawa 1974; Southwood 1974; Walker and Greenwald 1980; Takahashi and McPherron 1982; Southwood and Hughes 1983; Cheng et al. 1993; Cheng and Zaharia 2003). In the FLR model, when the ULF waves propagate in the magnetosphere, the Earth's dipole field lines behave like vibrating strings and have two major modes of oscillation, viz. toroidal and poloidal modes. The fundamental oscillation frequency of a field line in essence is associated with the speed of the Alfven wave along the field line. In addition, the harmonic related to both modes that has an odd (even) number of half wavelengths between two ends of a field line, viz. conjugate points, is termed "odd (even) mode". It is known that the radial and azimuthal perturbations of the odd (even) mode at the conjugate points are respectively in phase (out of phase) and out of phase (in phase). In addition to the ULF waves transmitted through the magnetopause, spatially evanescent waves generated at the magnetopause, e.g., the surface waves excited by KelvinHelmholtz (K-H) instability (Southwood 1968; Pu and Kivelson 1983; Miura 1987) when the magnetosheath plasma flow velocity exceeds a threshold velocity, are considered to be of another source for the excitation of FLRs. The second process is termed "cavity/waveguide resonance" (Radoski 1971; Kivelson et al. 1984; Allan et al. 1991; Samson et al. 1992; Ding et al. 1995; Rankin et al. 1995; Walker 1998; Waters et al. 2000; Keller and Lysak 2001), which has been successfully adopted for the explanation of the ULF waves with $f>\sim 1 \mathrm{mHz}$. Generally speaking, the doughnut-shaped cavity/waveguide is formed by the region bounded by the magnetopause, magnetosphere, and ionosphere. The cavity can be displaced by external forces, such as variations in the solar wind dynamic pressure, an azimuthally propagating wave along the magnetopause, and sudden impulses caused by interplanetary shocks, discontinuity, and reconnection. The disturbed cavity/waveguide supports the MHD waves of discrete frequencies. The excited waves stand along the field lines as well as in the radial direction, but travel along the azimuthal direction since the cavity is open in the azimuthal direction. On the other hand, the phase of each wave has a sign change across a node in the radial direction due to its standing-wave nature. It is also known that each wave can couple to a FLR of the same frequency somewhere in an evanescent tail (Waters et al. 2000) and leads to an enhancement of the azimuthal perturbation at the coupling point in the cavity.

This paper studies the global ULF geomagnetic pulsations related to the severe geomagnetic storm that occurred with storm sudden commencement (SSC) at 0341 UT on 24 March 1991. The index is shown in Fig. 1, and the bulk flow velocity of the solar wind inferred for this event at SSC reached $1400 \mathrm{~km} \mathrm{~s}^{-1}$ (Shea et al. 1993). During the main phase of storm time period, 0600 - 2200 UT, very prominent and global ULF pulsations of frequencies ranging from $0.83 \mathrm{mHz}$ (20 mins) to $3.3 \mathrm{mHz}$ ( 5 mins) were observed both in the magnetosphere and on the ground. Most of these ULF waves are categorized as the Pc 5 waves $(1.7<f$ $<6.7 \mathrm{mHz}$ ). The ground-based and satellite observations of the Pc 5 waves have been reported for a few decades (e.g., Brown et al. 1968; Barfield and McPherron 1972; Takahashi et al. 1986, 1987, 1990; Cahill and Winckler 1992; Kepko et al. 2002; Kepko and Spence 2003). Generally speaking, according to their dominant variations, these waves are categorized as compressional and transverse Pc 5 waves. Both waves show distinctly different wave characteristics, such as frequency, polarization, and phase propagation, while they are observed on either side of noon (e.g., Kokubun 1980; Yomoto et al. 1983; Kokubun et al. 1989; Anderson et al. 1990; Chisham and Orr 1997). For instance, a statistical study by Chisham and Orr (1997) demonstrated that the transverse waves predominately observed in the morning sector of the magnetosphere were well correlated with the ground-based observations, whereas the compressional waves observed in the afternoon sector of the magnetosphere were poorly correlated with the ground-based observations. Also, a series of studies particular on the compressional Pc 5 waves using data of the AMPTE/CCE spacecraft has been reported by Takahashi et al. (e.g., Takahashi et al. 1986, 1987, 1990). Specifically, Takahashi et al. (1990) presented observations of the second-harmonic Pc 5 waves, viz. the wave of the compressional variation oscillating at the second harmonic frequency of the transverse oscillation, both in the dawn and dusk sectors. Furthermore, several recent papers have reported observations of the ULF waves of discrete spectral peaks with $0.25<f<1 \mathrm{mHz}$ (Nikutowski et al. 1996) and with $1.3<f<3.4 \mathrm{mHz}$ (Ruohoniemi et al. 1991; Samson et al. 1991; Walker et al. 1992; Fenrich et al. 1995). With the demonstration of the correlations between the solar wind

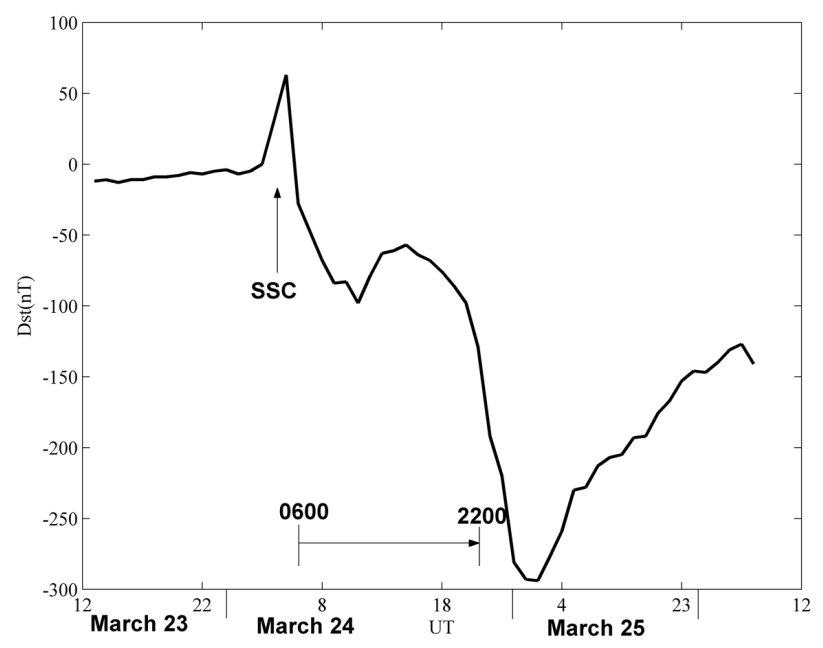

Fig. 1. Plot of the Dst Index. 
spectrum and the ULF wave spectrum, Kepko et al. (2002) and Kepko and Spence (2003) commented that the waves of this sort, particularly for the waves with $f<1 \mathrm{mHz}$, are sometimes directly driven by density oscillations present in the solar wind rather than the cavity/waveguide resonance.

To date, several studies on the event of 24 March 1991 have been reported in the literature (Cahill and Winckler 1992; Yumoto et al. 1992; Fujitani et al. 1993; Liu et al. 1993; Reddy et al. 1994; Trivedi et al. 1997; Schott et al. 1998). Most of these studies focused on a local investigation of the characteristics and driving causes of the pulsations through an analysis of the data obtained solely from ground stations or from satellites. This paper aims to study these storm-associated ULF pulsations via an analysis of the magnetic field data obtained from a global network, which consists of both ground-based observatories and geosynchronous satellites. Furthermore, the correlations between the ground and geosynchronous observations are presented. This paper is organized as follows. The characteristics of the pulsations in the magnetosphere and on the ground along with their correlations are described respectively in section 2 . Section 3 presents the data interpretations according to the correlations between the geosynchronous and ground observations.

\section{OBSERVATIONS}

To investigate characteristics of the ULF pulsations, the magnetic field data recorded during 1000 - 2200 UT at a global network, which is comprised of 37 ground observatories and 2 geosynchronous satellites, GOES 6 and 7, in the magnetosphere, are analyzed. The wave characteristics in the magnetosphere as well as on the ground during the two primary time spans, $1000-1400$ and $1800-2200$ UT, are described herein. The ground observatories include the INTERMAGNET observatories and 210MM observatories, and the coordinates of the 37 ground-based observatories are listed in Table 1. This network provided us with a look at the pulsations on the ground as well as in the magnetosphere. More importantly, the correlations between the ground and geosynchronous observations can be developed via this network.

Here, to further analyze the spatial and temporal characteristics of the ULF geomagnetic pulsations, twenty-nine ground observatories that observed prominent ULF pulsations of $1.67<f<2.78 \mathrm{mHz}$ are chosen and divided into three regions, viz. Region A $\left(50-65^{\circ} \mathrm{N}, 80-120^{\circ} \mathrm{E}\right), \mathrm{B}(35-$ $\left.80^{\circ} \mathrm{N}, 275-360^{\circ} \mathrm{E}\right)$, and $\mathrm{C}\left(40^{\circ} \mathrm{N}-50^{\circ} \mathrm{S}, 210^{\circ} \mathrm{E}\right)$, according to their geographical locations (Fig. 2a). The relative location of each region to the Sun at various universal time intervals is depicted in Fig. 2b. In Fig. 2b, the view is downward on the equatorial plane from the north pole of the Earth. The solid curve of a wider width represents the longitudinal coverage of each region, and the thinner one represents the trajectory of each region while it was moving from the start of each time span to the end of each time span. The spatial and temporal characteristics of the geomagnetic pulsations are monitored by these three regions. Similarly, the pulsations in the magnetosphere are investigated using GOES 6 and 7. The relative location of GOES 6 and 7 satellites to the Sun at the same time intervals is depicted in Fig. 3a. In addition, local time of the ground observatories relative to the satellites is shown in Fig. 3b. In what follows, the characteristics of the ULF waves in the magnetosphere and on the ground are described in sections 2.1 and 2.2, respectively. Section 2.3 presents the correlations between the geosynchronous and ground observations.

\subsection{Geosynchronous Observations}

The magnetic field data obtained from GOES 6 and 7 are originally represented in the $\mathrm{Hp}, \mathrm{Hn}$ and $\mathrm{He}$ components, where the Hp component is parallel to the satellite's spin axis, the Hn component is the positive northward component, and the He component is the positive eastward component. In this paper, the $(\mathrm{Hp}, \mathrm{Hn}, \mathrm{He})$ system is rotated into the local dipole field aligned system employed by Takahashi et al. (1990). The local dipole field aligned system represents the data in the $\mathrm{B}, \mathrm{V}$, and $\mathrm{D}$ components, where the B component is parallel to the Earth's magnetic dipole axis, the $\mathrm{V}$ component points radially outward in a plane parallel to the magnetic equatorial plane, and the D component points toward the east. With this representation, it is easier to determine the compressional/transverse waves according to their dominant variations.

All the data are filtered through a $1.67-2.78 \mathrm{mHz}(6$ - $10 \mathrm{~min}$ ) passband since this band contains the major components in the spectrum. In Fig. 4, the variations of the B, D, and $\mathrm{V}$ components of the magnetic field recorded at GOES 6 as well as GOES 7 during 1000 - 1400 UT are plotted respectively. Both satellites were moving from post-midnight to dawn in the magnetosphere. It shows all the components had very regular and wave-packet like fluctuations, and the transverse $\mathrm{D}$ and $\mathrm{V}$ components were the dominant fluctuations at both GOES 6 and 7. This observation agrees with the aforementioned Pc 5 characteristics reported by $\mathrm{Ch}$ isham and Orr (1997). Likewise, the variations of the B, D, and $\mathrm{V}$ components of the magnetic field recorded at GOES 6 and GOES 7 during 1800 - 2200 UT are plotted in Fig. 5, respectively. Both satellites were moving around the noon sector. During this time span, the regular and wave-packet like fluctuations were also observed at both satellites. The compressional B component variation along with the transverse $\mathrm{D}$ component variation had the dominant fluctuations. Specifically, the compressional component variation detected at GOES 6 during 1930 - 2020 UT as well as 2100 2130 UT and at GOES 7 during 2030 - 2100 UT was significantly enhanced. As for the D component variation, the one 
Table 1. List of the geographical and geomagnetic coordinates of the observatories.

\begin{tabular}{|c|c|c|c|c|c|}
\hline \multirow[b]{2}{*}{ Station name } & \multirow[b]{2}{*}{ Code } & \multicolumn{2}{|c|}{ Geographic } & \multicolumn{2}{|c|}{ Geomagnetic } \\
\hline & & Latitude & Longitude & Latitude & Longitude \\
\hline Adelaide & $\mathrm{ADE}$ & -34.67 & 138.65 & -46.72 & 213.34 \\
\hline Bay St. Louis & BSL & 30.35 & -89.64 & 40.40 & 339.40 \\
\hline Boulder & $\mathrm{BOU}$ & 40.14 & -105.24 & 48.80 & 319.60 \\
\hline Brorfelde & $\mathrm{BFE}$ & 55.63 & 11.67 & 55.50 & 98.70 \\
\hline Barrow & BRW & 71.32 & -156.62 & 69.30 & 244.50 \\
\hline Birdsville & BSV & -25.54 & 139.21 & -36.58 & 212.96 \\
\hline Cambridge Bay & $\mathrm{CBB}$ & 69.10 & -105.00 & 76.70 & 300.40 \\
\hline Chambon la Forêt & CLF & 48.02 & 2.27 & 50.00 & 85.70 \\
\hline Chichijima & CBI & 27.15 & 142.30 & 20.65 & 212.74 \\
\hline College & $\mathrm{CMO}$ & 64.87 & -147.86 & 65.10 & 260.30 \\
\hline Del Rio & DLR & 29.50 & -100.92 & 38.60 & 326.50 \\
\hline Dumont d'Urville & DRV & -66.37 & 140.01 & -74.90 & 232.00 \\
\hline Eskdalemuir & ESK & 55.32 & -3.20 & 58.00 & 84.10 \\
\hline Fort Churchill & FCC & 58.77 & -94.10 & 68.30 & 327.00 \\
\hline Fredericksburg & FRD & 38.20 & -77.37 & 48.90 & 352.80 \\
\hline Fresno & FRN & 37.09 & -119.72 & 43.70 & 304.30 \\
\hline Godhavn & GDH & 69.25 & -53.30 & 79.00 & 34.60 \\
\hline Guam & GUA & 13.59 & 144.87 & 4.80 & 215.00 \\
\hline Hartland & HAD & 51.00 & -4.48 & 54.10 & 80.40 \\
\hline Kagoshima & KAK & 31.48 & 130.72 & 25.23 & 201.99 \\
\hline Lerwick & LER & 60.13 & -1.18 & 62.10 & 89.50 \\
\hline Lovo & LOV & 59.40 & 17.80 & 57.90 & 106.70 \\
\hline Meanook & MEA & 54.62 & -113.33 & 61.80 & 304.80 \\
\hline Mould Bay & MBC & 76.20 & -119.40 & 79.70 & 261.90 \\
\hline Moshiri & MSR & 44.37 & 142.27 & 37.76 & 212.96 \\
\hline Nurmijarvi & NUR & 57.70 & 24.70 & 55.10 & 111.80 \\
\hline Narssarssauaq & NAQ & 61.16 & -45.44 & 70.30 & 39.00 \\
\hline Port-aux-Francais & PAF & -49.35 & 70.26 & -57.20 & 131.50 \\
\hline Pamatati & PPT & -17.57 & -149.57 & -15.10 & 284.80 \\
\hline Sitka & SIT & 57.06 & -135.33 & 60.30 & 278.90 \\
\hline San juan & SJG & 18.11 & -66.50 & 28.80 & 5.60 \\
\hline Sodankyla & SOD & 67.37 & 26.63 & 63.70 & 120.50 \\
\hline St john’s & STJ & 47.60 & -52.68 & 57.70 & 23.70 \\
\hline Tucson & TUC & 32.18 & -110.73 & 40.20 & 315.10 \\
\hline Thule & THL & 77.47 & -69.23 & 88.20 & 14.80 \\
\hline Victoria & VIC & 48.52 & -123.42 & 54.30 & 296.40 \\
\hline Weipa & WEP & -12.68 & 141.88 & -22.99 & 214.34 \\
\hline
\end{tabular}


(a)

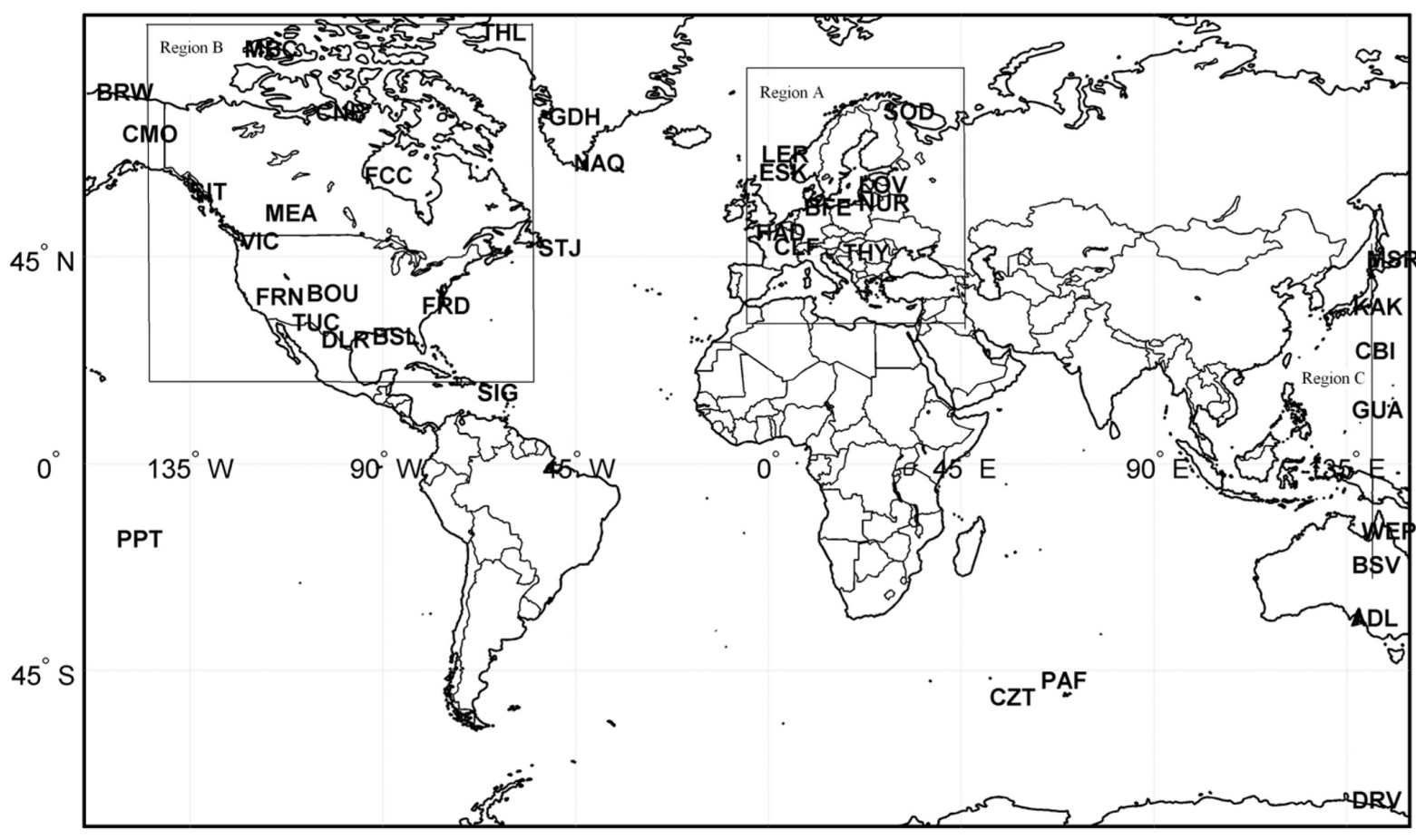

(b) SUN

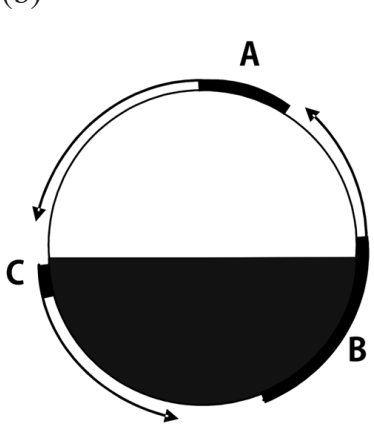

1000-1400UT

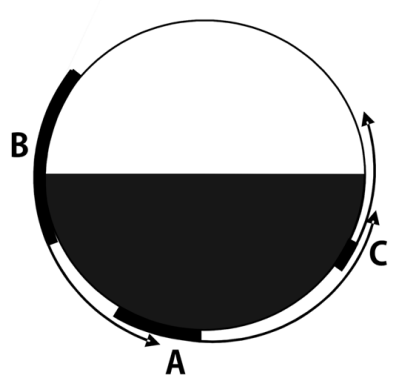

1800-2200UT
Fig. 2. (a) Geographical locations of Regions A, B, and $\mathrm{C}$. (b) Pictorial description of the relative locations of Regions A, B, and C to the Sun from 1000 to 1400 UT and from 1800 - 2200 UT. (a)

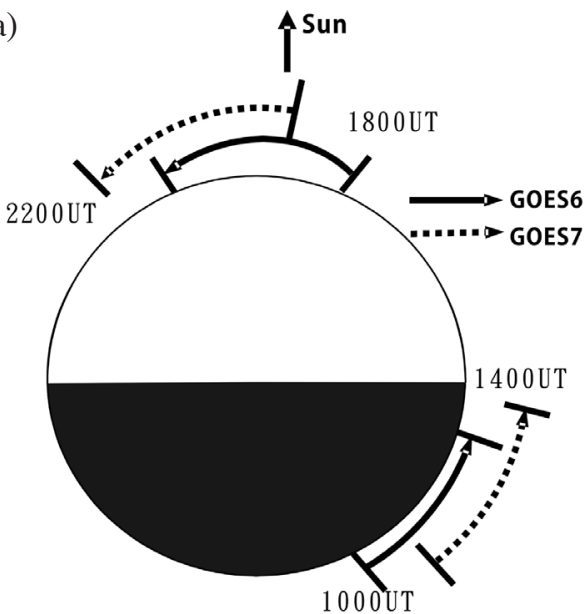

(b)

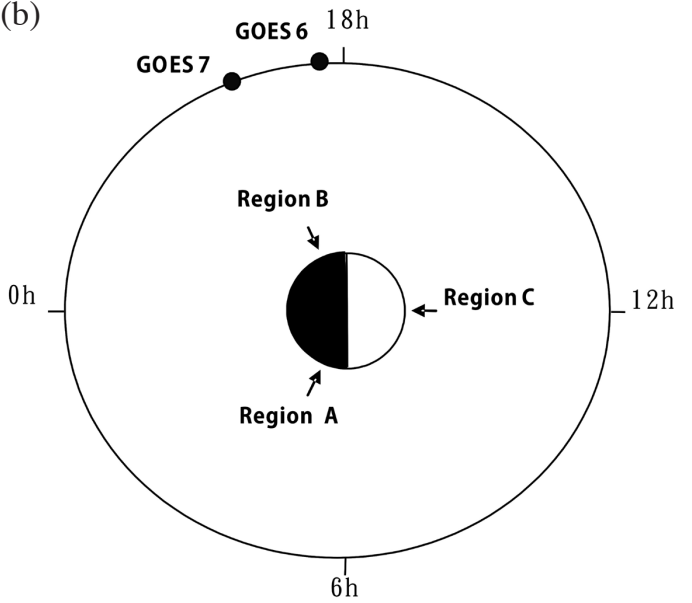

Fig. 3. (a) Pictorial description of the relative locations of GOES 6 and GOES 7 from 1000 to 1400 UT and from 1800 to 2200 UT. (b) Pictorial description of the local time of the ground observatories relative to the satellites. 

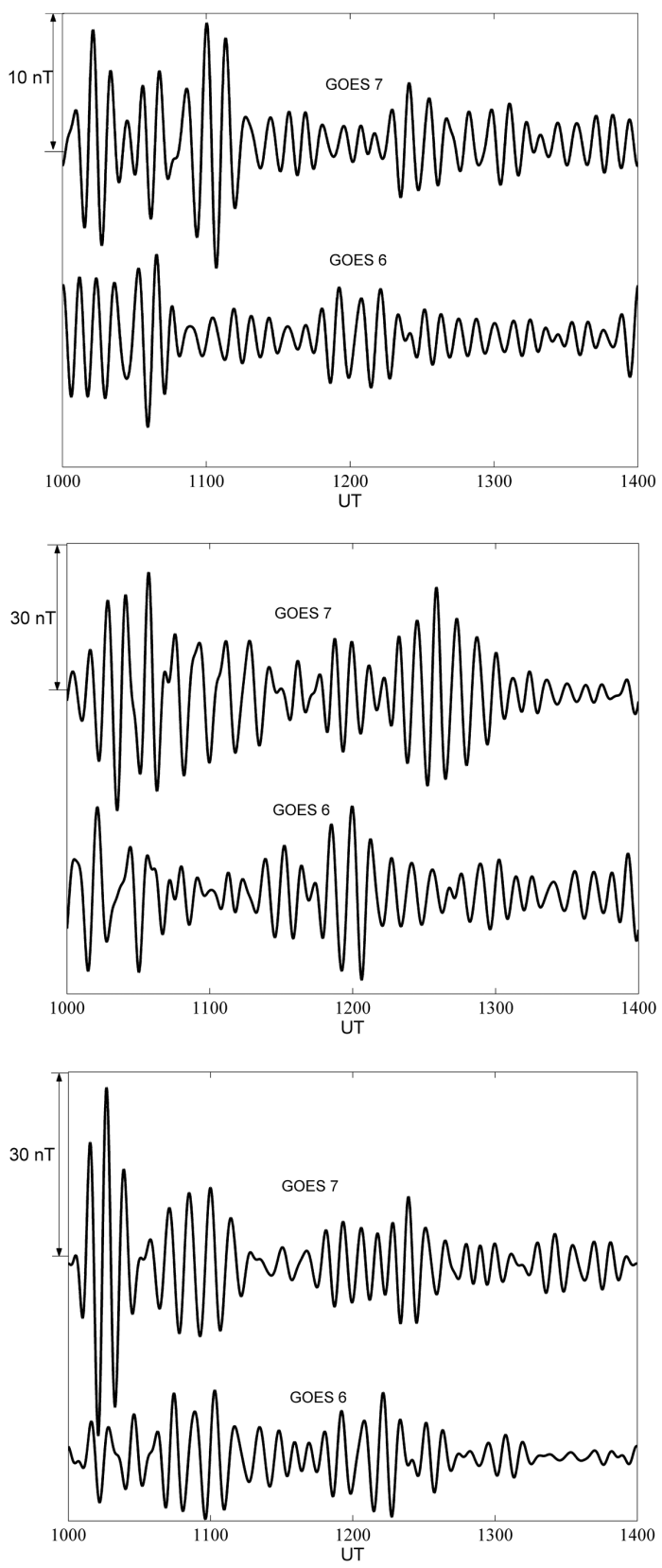

Fig. 4. Time signatures of the B (top), D (middle), and V (bottom) components of the magnetosphere's magnetic field measured at GOES 6 and 7 during $1000-1400$ UT.

detected at GOES 6 had very strong variation during 1930 2020 UT while the one detected at GOES 7 showed consistently dominant variation during the whole time span.

\subsection{Ground Observation}

As mentioned earlier, the magnetic field data on the ground were obtained from INTERMAGNET stations and 210MM stations. All the data have a resolution of one minute. Most of the ground-based data are represented in
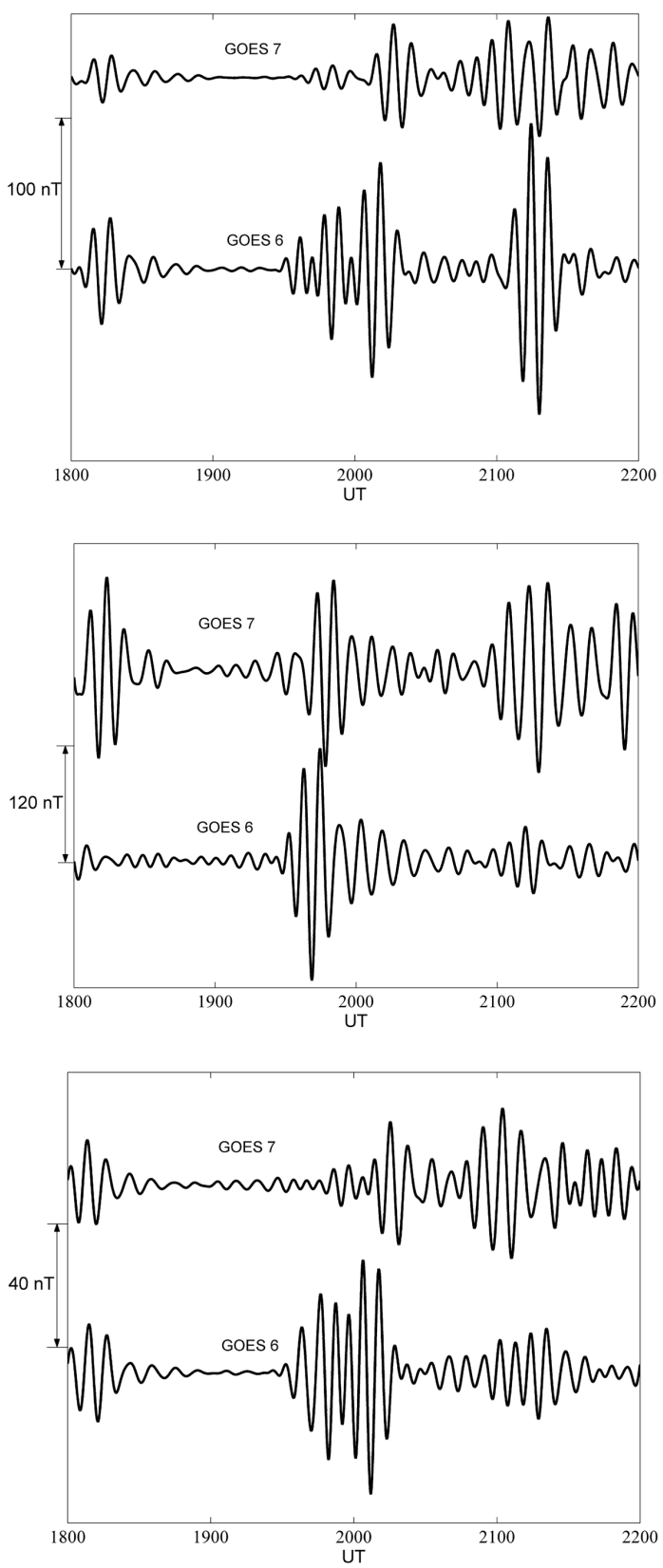

Fig. 5. Time signatures of the B (top), D (middle), and V (bottom) components of the magnetosphere's magnetic field measured at GOES 6 and 7 during $1800-2200$ UT.

HDZ coordinates, where the $\mathrm{H}$ component is the horizontal component, the $\mathrm{D}$ component denotes the declination, and the $\mathrm{Z}$ component is the vertical component pointing to the Earth's center. Only a few ground-based data, such as the data from 210MM stations, are in XYZ coordinates where the $\mathrm{X}$ component is the geographical north component, the $\mathrm{Y}$ component is the geographical east component, and the $\mathrm{Z}$ component is the vertical component pointing to the Earth's center. Here, the XYZ coordinates are rotated into HDZ coordinates for consistent data presentation. 
First, the spatial variation of the pulsation intensity is presented. During 1000 - 2200 UT, the maximum amplitude of the pulsations observed at each observatory is plotted against its geomagnetic latitude (Fig. 6). As shown in Fig. 6, the perturbation in all the components increased with the geomagnetic latitude except that there is an intensity drop at the station $\mathrm{CBB}\left(76.7^{\circ} \mathrm{N}\right)$ that is situated under the magnetospheric cleft region. For instance, the amplitude of the $\mathrm{H}$ component variation detected at GUA $\left(4.27^{\circ} \mathrm{N}\right)$, $\operatorname{CLF}\left(50^{\circ} \mathrm{N}\right)$, and GDH $\left(79^{\circ} \mathrm{N}\right)$ was $4 \mathrm{nT}, 40 \mathrm{nT}$, and $100 \mathrm{nT}$, respectively. Note the latitude specified in the parentheses and in the rest of the context is in geomagnetic coordinates. On the other hand, the strongest intensity was observed in both Regions A and C during the period of 0720 - 0900 UT. As depicted in Fig. 2b, Regions A and $\mathrm{C}$ were located around the dawn and dusk sides during this period of time, respectively.

Next, the frequency characteristic and the time signature of the ULF waves during the two time spans, i.e., 1000 1400 and 1800 - 2200 UT, are described, respectively. During 1000 - 1400 UT, global and prominent geomagnetic pulsations were observed. For instance, Figs. 7a, b, and c show the spectrums of the $\mathrm{H}, \mathrm{D}$, and $\mathrm{Z}$ components at 9 ground stations (3 stations in each region) during 1000 - 1400 UT, respectively. More specifically, the first, second, and third rows of each figure show the spectrums of the three stations in Regions A, B, and C, respectively. It appears that the pulsations showed discrete spectrums in all components. Below, the frequency characteristics of the waves are pre- sented. Regarding the spectrum distribution, as shown in the Figs. $7 \mathrm{a}, \mathrm{b}$, and c, the waves of $1.1<f<2 \mathrm{mHz}$ were observed at all observatories, and the peaks of $f<1 \mathrm{mHz}$ were observed at the stations in Regions $\mathrm{A}$ and $\mathrm{C}$, which were located on the day side and on the dusk side respectively. To study the temporal variation of the pulsations, all the data are filtered through the same bandpass filter used for the geosynchronous analysis. The filtered time signatures of the $\mathrm{H}, \mathrm{D}$, and $\mathrm{Z}$ components at 9 ground stations are demonstrated in Figs. 8a, b, and c, respectively. Similar to the pulsations in the magnetosphere, regular and wave-packetlike perturbations were observed at the ground stations. The stations in Regions $\mathrm{A}$ and $\mathrm{C}$ measured dominant variations in the $\mathrm{H}$ and D components, especially during $1000-1030$ UT. As for the stations in Region B, dominant variations in the $\mathrm{H}$ component were observed. Regarding the frequency characteristics of the waves during the time span 1800 $2200 \mathrm{UT}$, the spectrums of the $\mathrm{H}, \mathrm{D}$, and $\mathrm{Z}$ components at the same 9 ground stations are demonstrated in Figs. 9a, $\mathrm{b}$, and c, respectively. Similarly, the discrete spectrums in all components were observed. However, the stations in Region B showed more continuous spectrums, especially in the $\mathrm{Z}$ component. For each geomagnetic field component, the spectral peaks of $0.65<f<2 \mathrm{mHz}$ were observed at all stations. Compared to the time span 1000 - 1400 UT, it appears that the spectral peaks of $f<1 \mathrm{mHz}$ were dominant at all the stations. Their filtered time signatures of the $\mathrm{H}, \mathrm{D}$, and $\mathrm{Z}$ components are demonstrated in Figs. 10a, b, and c, respectively. During this time span, the stations in Regions
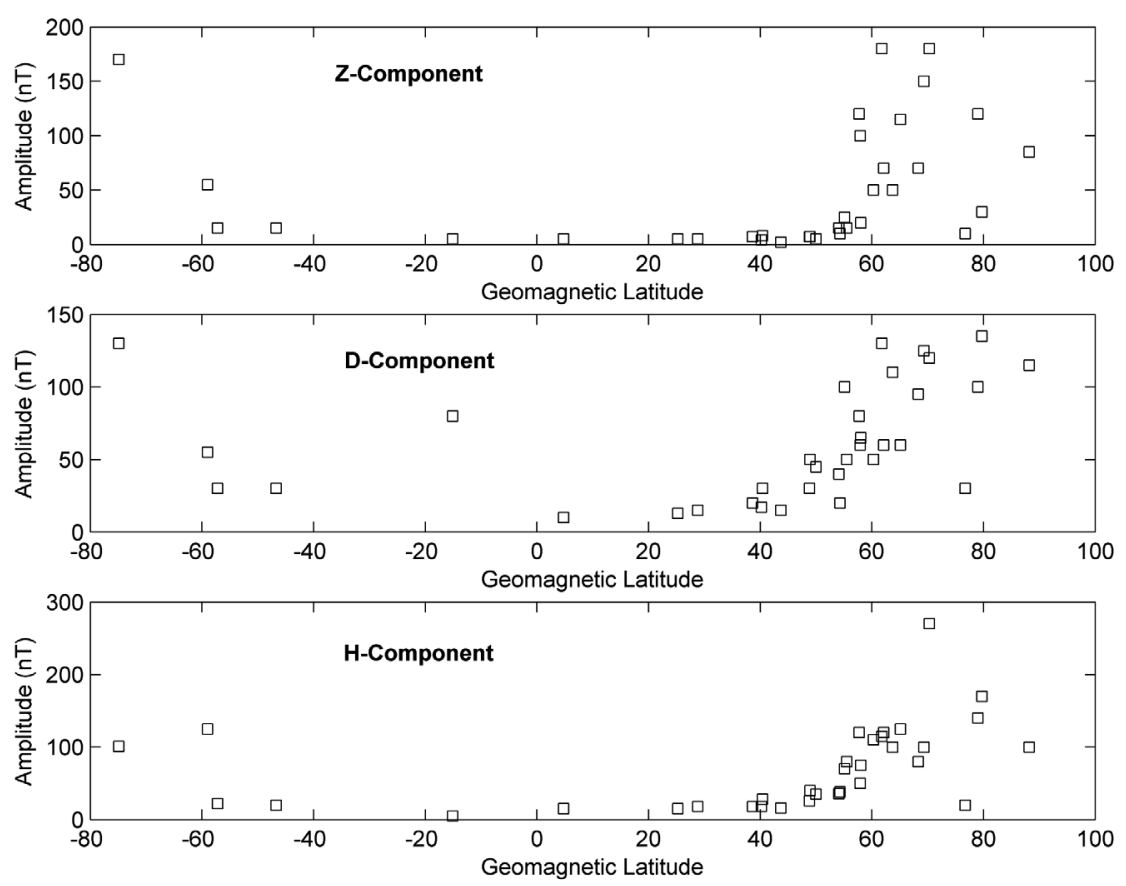

Fig. 6. Latitudinal variations of the maximum perturbations of the $\mathrm{H}, \mathrm{D}$, and $\mathrm{Z}$ components measured at the ground observatories during 0600 2200 UT. 
298

Nan-Wei Chen \& Jann-Yenq Lu

(a)
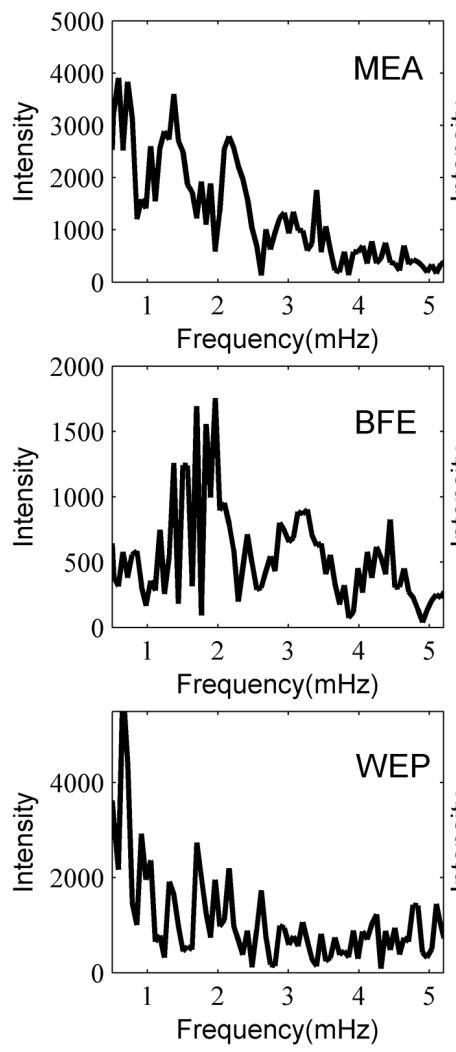

(b)
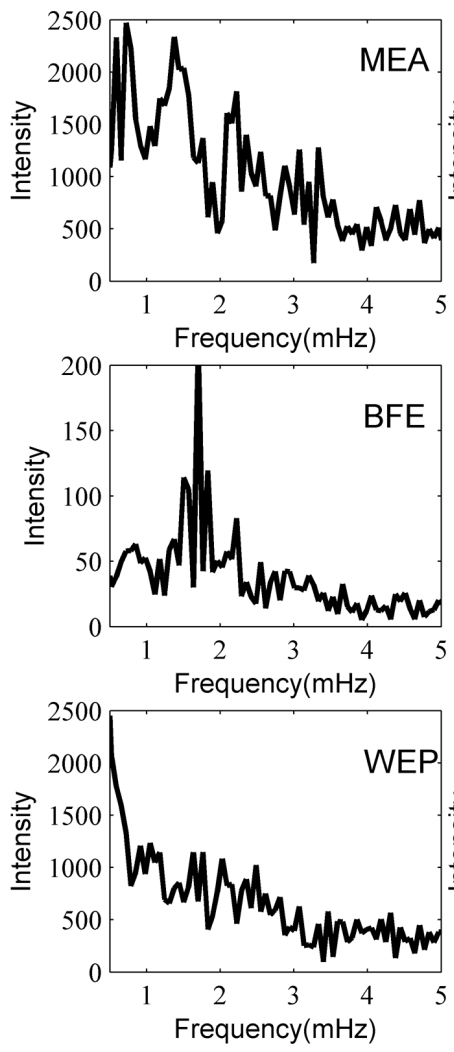
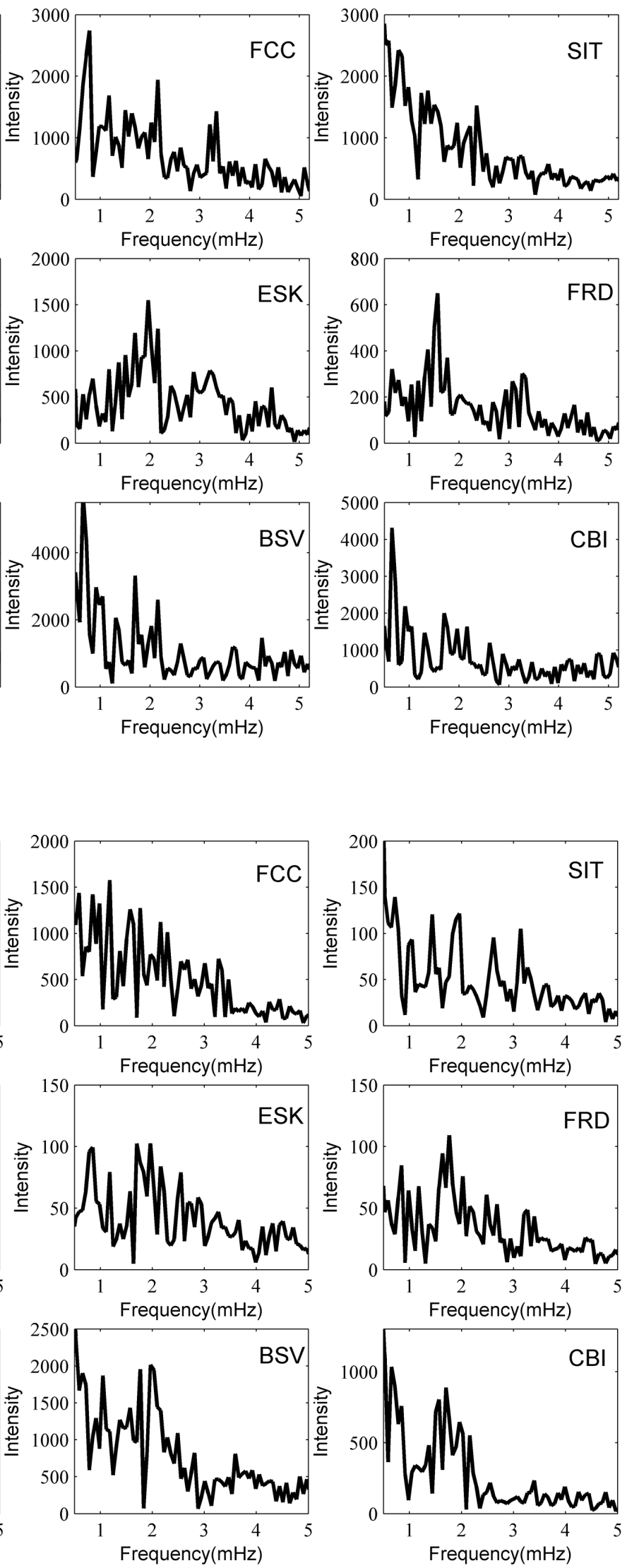

Fig. 7. (a) Spectrum distributions of the H-component variations at the ground stations during 1000 - 1400 UT. (b) Spectrum distributions of the D-component variations at the ground stations during 1000 - 1400 UT. (c) Spectrum distributions of the Z-component variations at the ground statons during 1000 - 1400 UT. 
(c)
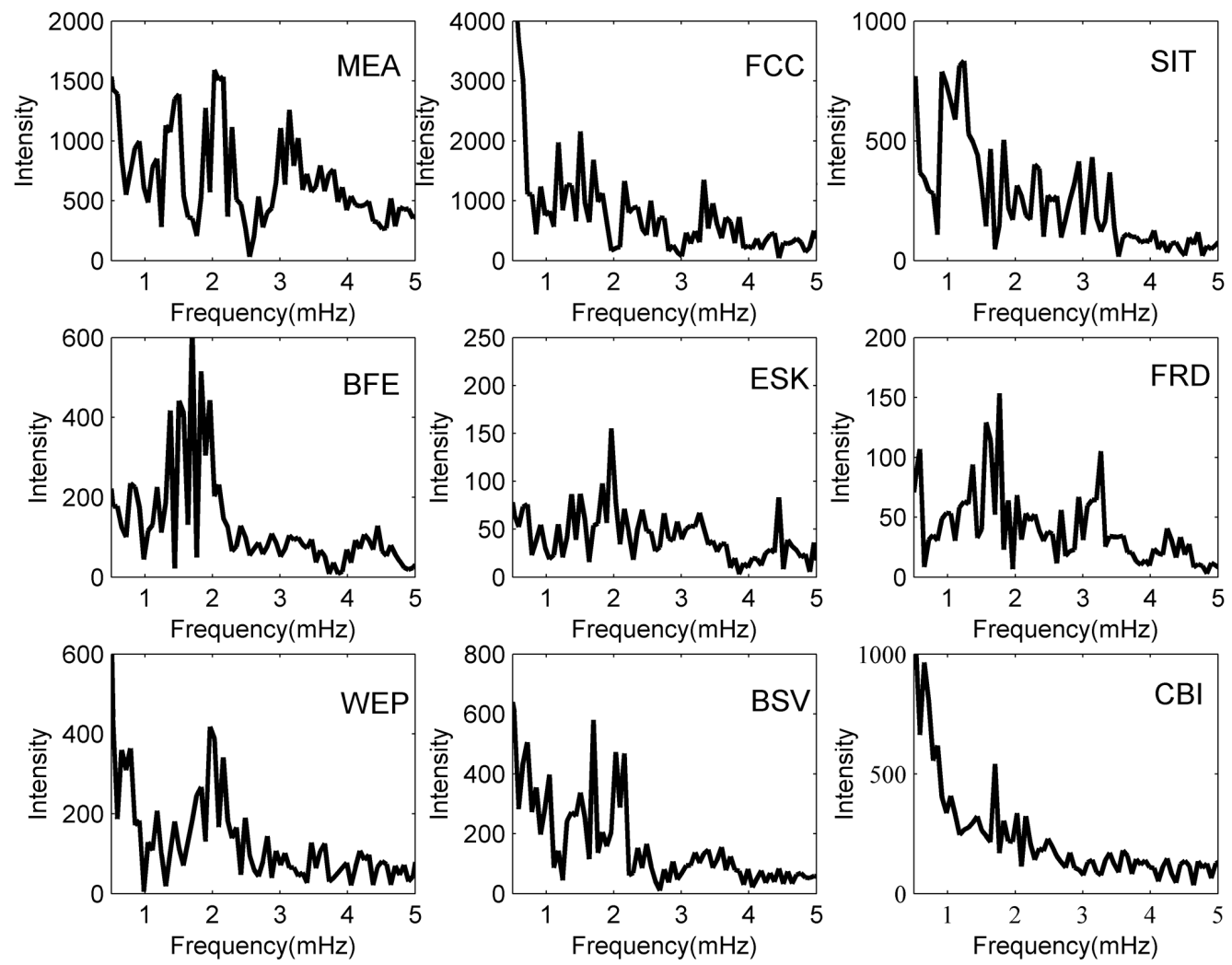

Fig. 7. (Continued)

(a)

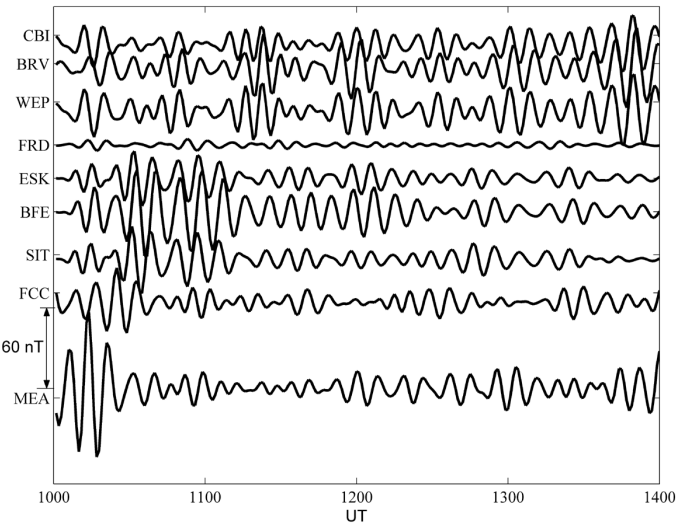

(c)

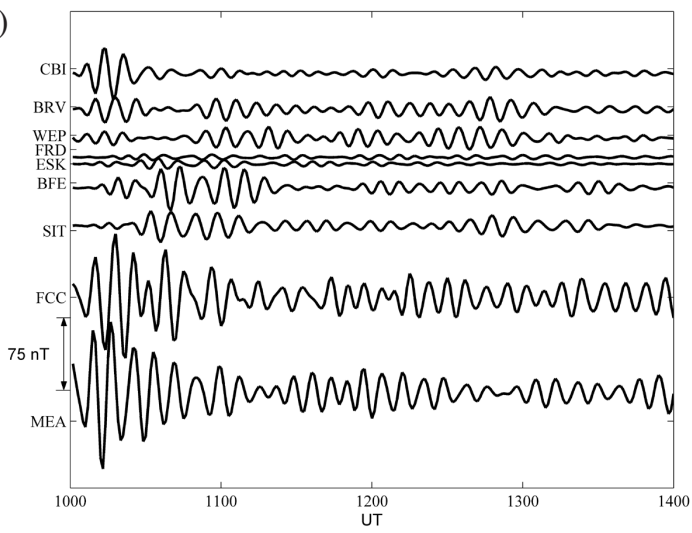

(b)

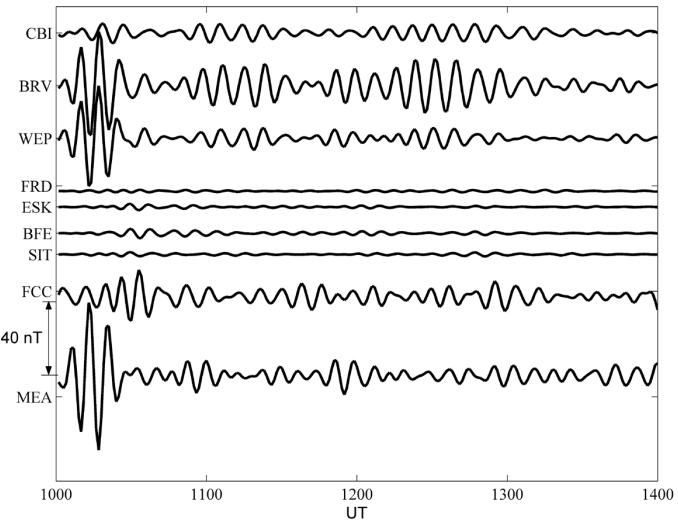

Fig. 8. (a) Time signatures of the H-component variations at the ground stations during 1000 - 1400 UT. (b) Time signatures of the D-component variations at the ground stations during $1000-1400$ UT. (c) Time signatures of the $\mathrm{Z}$-component variations at the ground stations during 1000 - 1400 UT. 
300

Nan-Wei Chen \& Jann-Yenq Lu

(a)
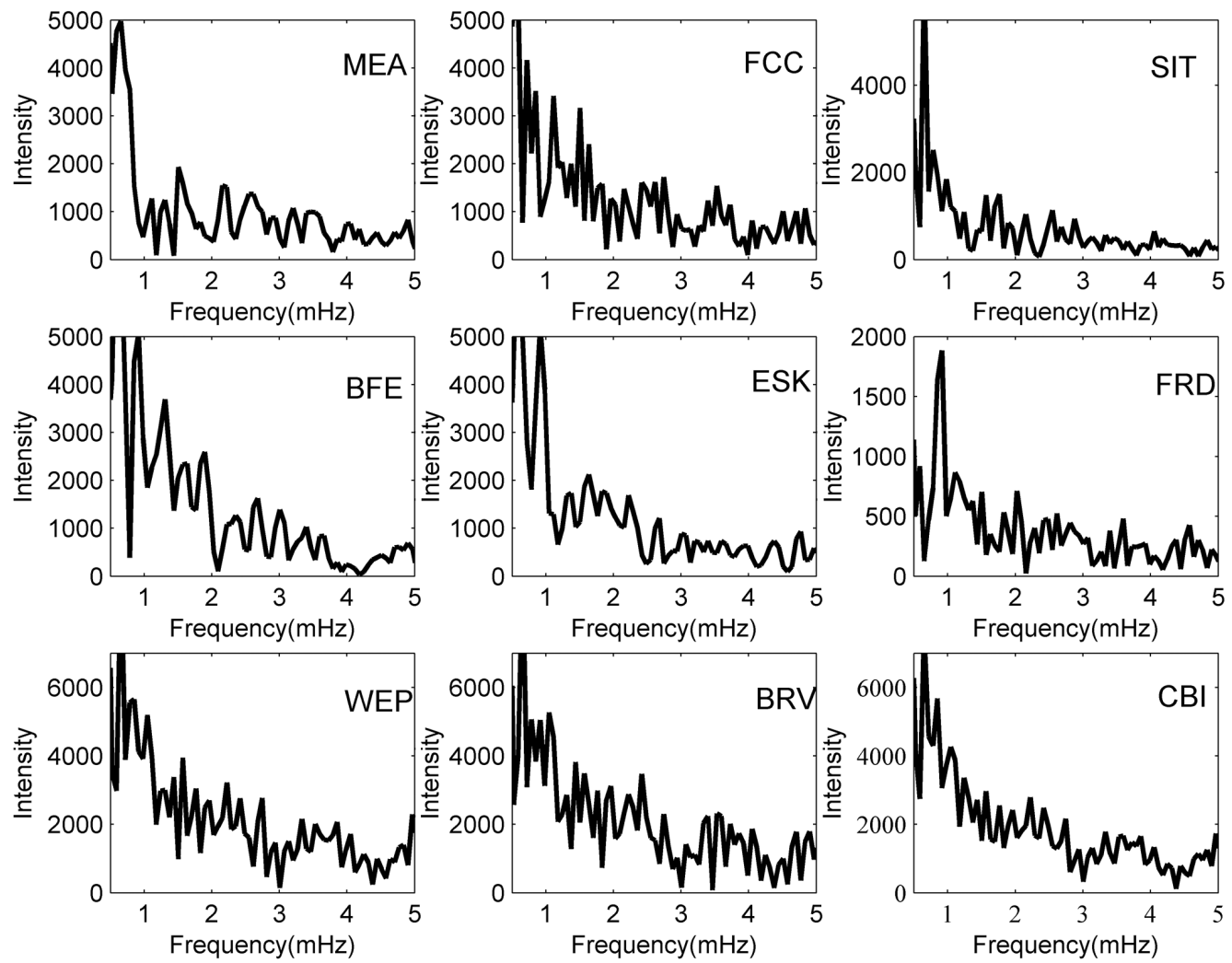

(b)
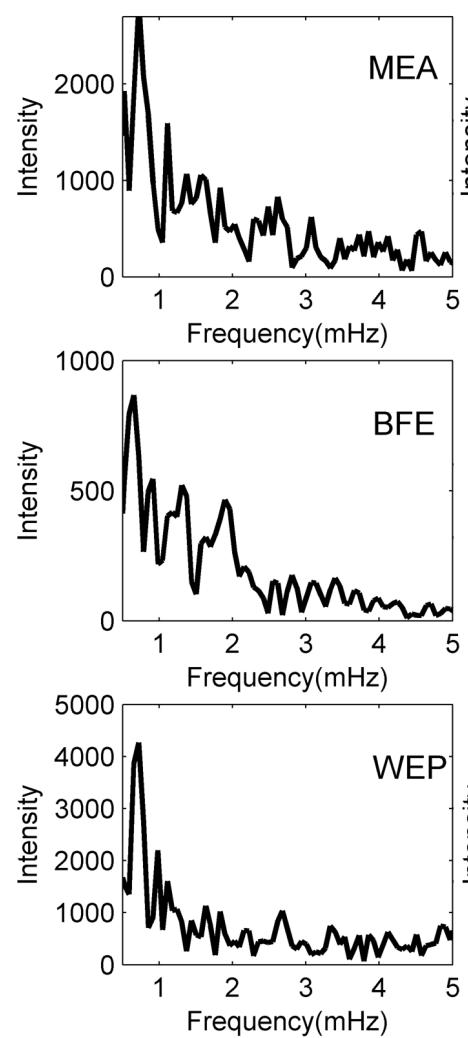
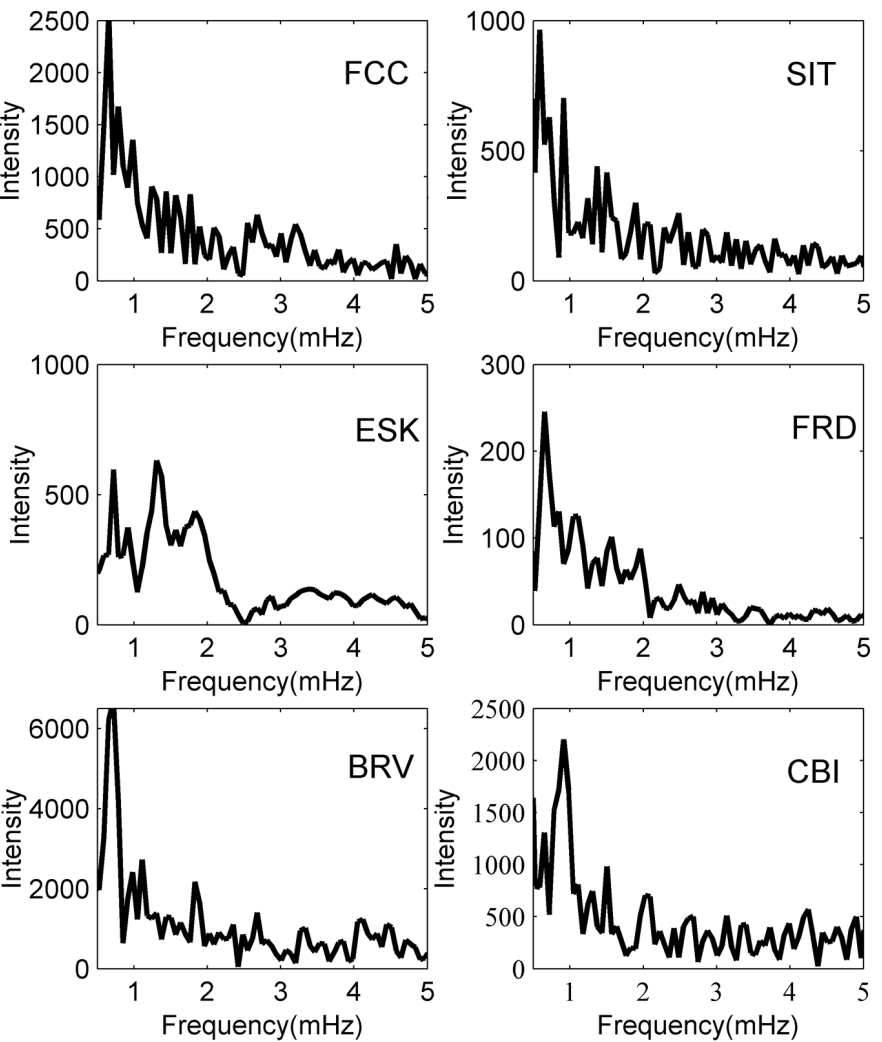

Fig. 9. (a) Spectrum distributions of the H-component variations at the ground stations during $1800-2200$ UT. (b) Spectrum distributions of the D-component variations at the ground stations during 1800 - 2200 UT. (c) Spectrum distributions of the Z-component variations at the ground statons during 1800 - 2200 UT. 
(c)
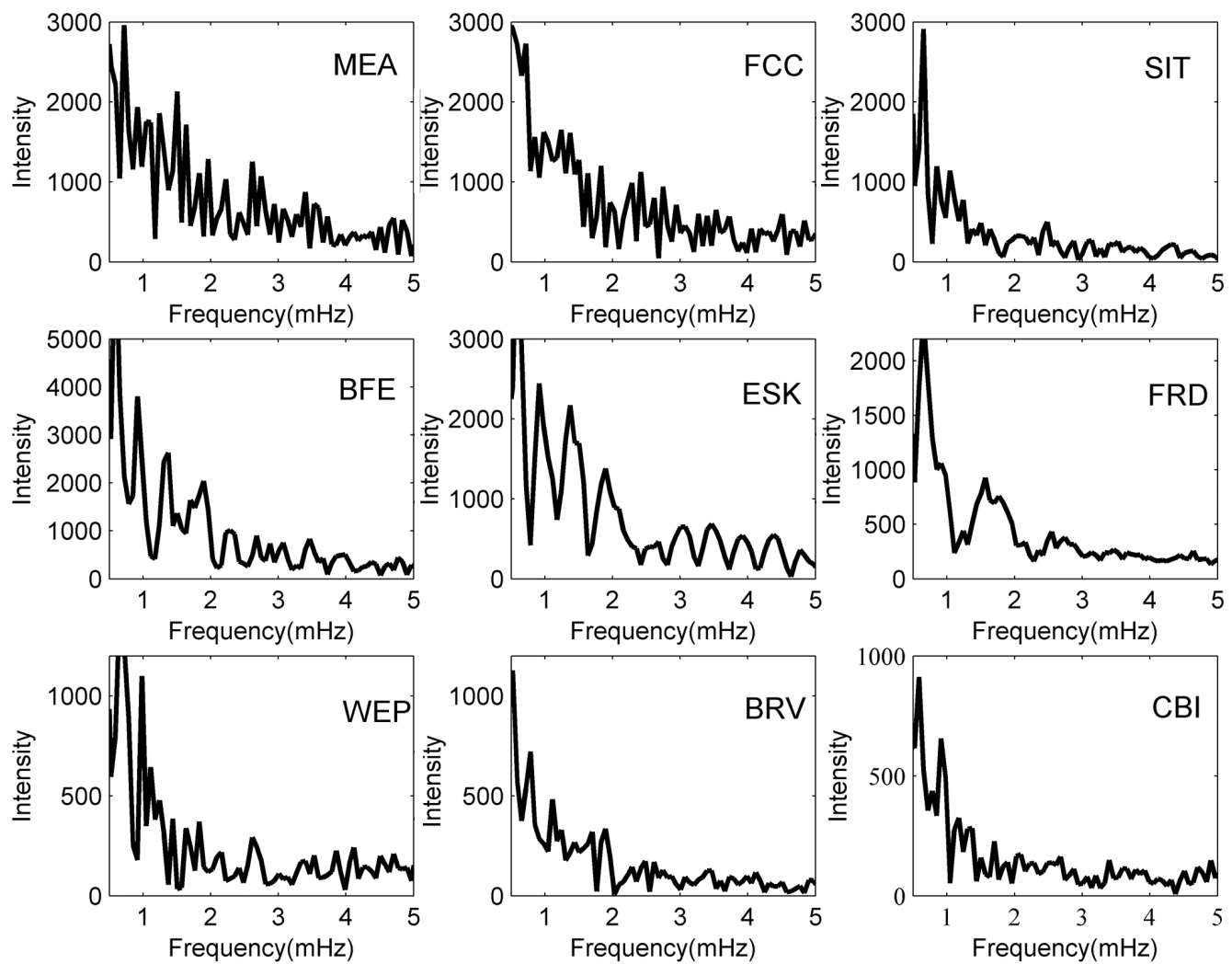

Fig. 9. (Continued)

(a)

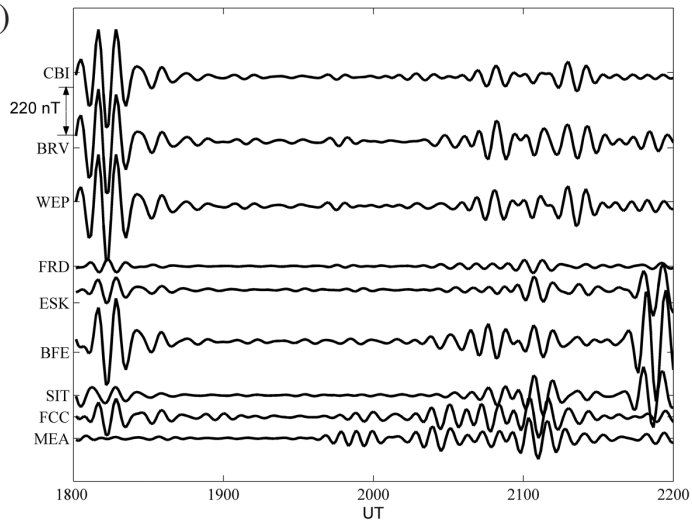

(c)

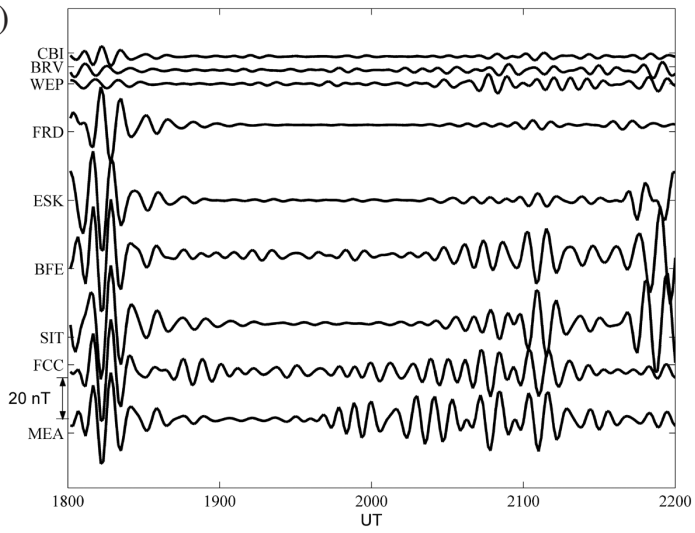

(b)

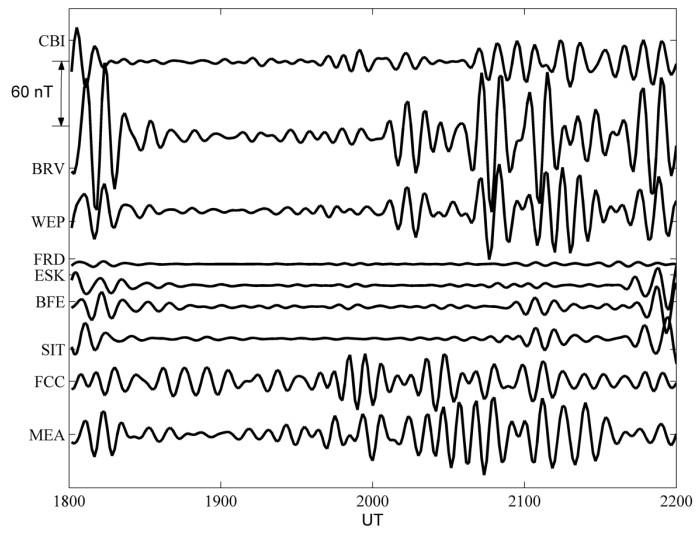

Fig. 10. (a) Time signatures of the H-component variations at the ground stations during 1800 - 2200 UT. (b) Time signatures of the D-component variations at the ground stations during $1800-2200$ UT. (c) Time signatures of the Z-component variations at the ground stations during 1800 - 2200 UT. 
$\mathrm{A}$ and $\mathrm{B}$ showed dominant variations in the $\mathrm{H}$ and $\mathrm{Z}$ components, particularly during 1800 - 1840 and 2030 - 2200 UT. As for the stations in Region C, the $\mathrm{H}$ component was the dominant variation during 1800 - 1850 UT while both the $\mathrm{H}$ and $\mathrm{D}$ components became the dominant variation during 2020 - 2200 UT.

Following the polarization of the pulsations is described. To study the wave polarization, the $\mathrm{H}$ and $\mathrm{D}$ components of the magnetic field data recorded at each region are used for the hodogram analysis. As shown in Fig. 11, the polarization of the waves observed at 8 stations in Region B is demonstrated. The counterclockwise elliptical polarization was observed during 1000 - $1100 \mathrm{UT}$, and the sense of rotation was reversed to clockwise during 1100 - 1200 UT.
Besides, the quasi-linear polarization was observed prior to the reversal. The reversal time is $1130 \mathrm{UT}$ at BFE and CLF and 1140 UT at ESK, HAD, LER, LOV, and NUR. As depicted in Fig. $2 b$, these observatories were located near the noon stagnation point during the reversal. In Region B, the elliptical polarization was also observed during 1000 1300 UT. The sense of rotation was mainly counterclockwise during 1100 - 1200 UT, whereas the sense of rotation switched alternatively from counterclockwise to clockwise during 10000 - 1100 and 1200 - 1300 UT. The elliptical and linear polarization observed in Regions A and B are likely to be the results of the propagation of the poloidal and toroidal waves in the magnetosphere respectively. As for Region $\mathrm{C}$, the observatories at the northern hemisphere observed

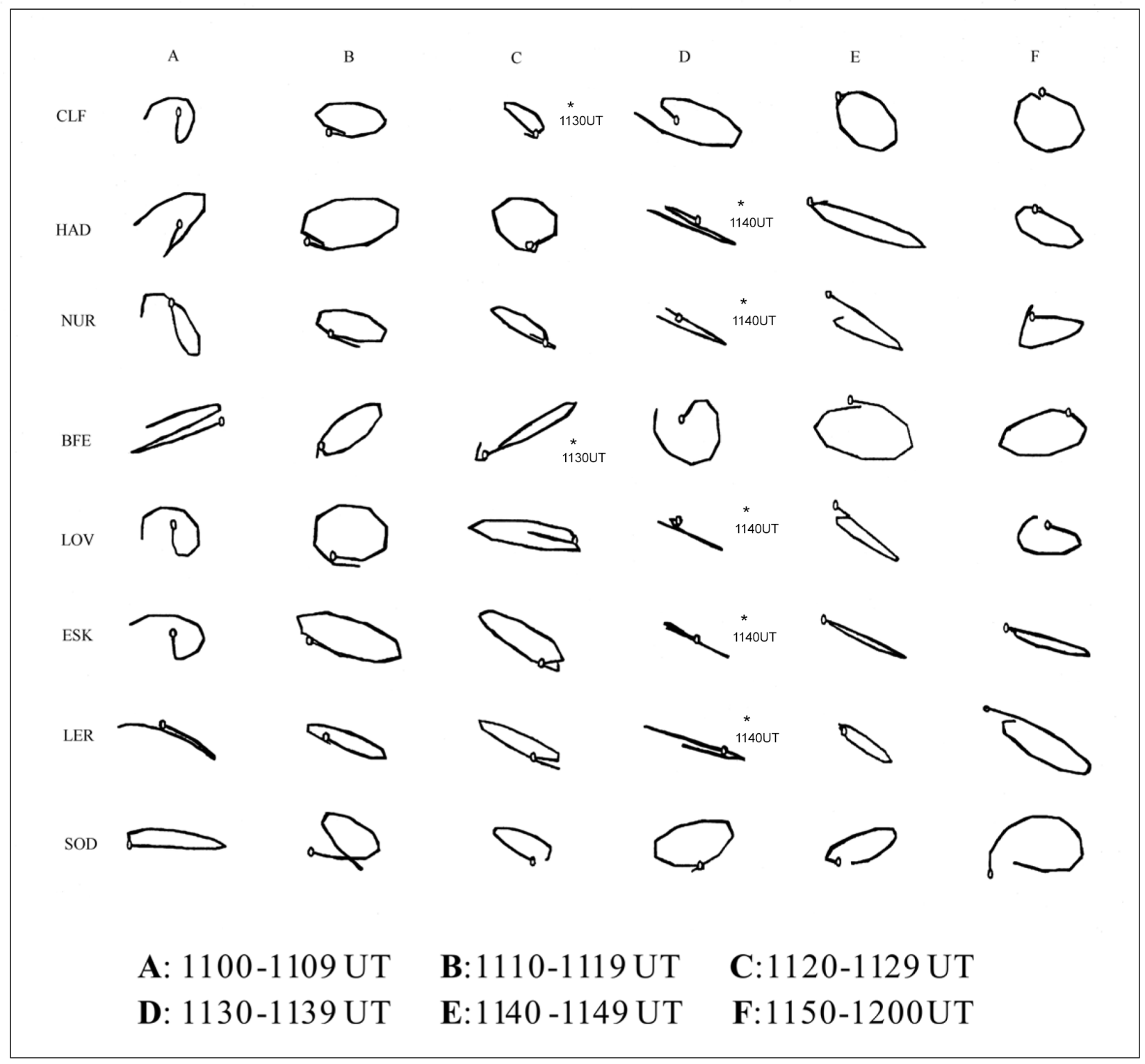

Fig. 11. Polarizations of the geomagnetic field variations at the observatories CLF, HAD, NUR, BFE, LOV, ESK, LER, and SOD during 1100 1200 UT ( $\bigcirc$ : starting mark, * : reversal time of the polarization). 
a clockwise elliptical polarization, whereas a counterclockwise elliptical polarization was detected at the observatories at the southern hemisphere. To further understand the oscillation mode of the field lines, the data obtained from two conjugate observatories, MSR $\left(37.8^{\circ} \mathrm{N}\right)$ and $\mathrm{BSV}\left(-37.1^{\circ} \mathrm{S}\right)$, were used to study magnetic conjugacy. To specifically investigate the Pc 5 waves with a period of $9-10 \mathrm{~min}$, the data are filtered with a bandpass filter of a $9-10$ min passband. The filtered $\mathrm{H}$ and $\mathrm{D}$ component variations at MSR and BSV during 1000 - 1400 UT are plotted in Fig. 12. Crosscorrelation analysis was employed to the filtered signals to find their phase relationship. The estimated phase differences of the $\mathrm{H}$ and $\mathrm{D}$ components at the conjugate points were $30^{\circ}$ and $160^{\circ}$, respectively. Furthermore, as shown in Fig. 13, the polarization of the variations was symmetric to the geomagnetic equatorial plane during 1200 - 1300 UT. The analysis showed that the oscillation of the field line associated with the two conjugate points was in odd mode. The north-south symmetry of the H-component and antisymmetry of the D-component for compressional Pc 5 waves was explained by the theory presented by Cheng and Lin (1987) and Cheng and Qian (1994).
Finally, the propagation of geomagnetic pulsations is investigated. Under the assumption of plane wave propagation, the azimuthal and latitudinal wave number of the pulsations, denoted as $m$ and $l$ respectively, can be defined according to the phase relationship among three nearby stations (Tonegawa and Sato 1987). Specifically, the phase of the plane wave varies linearly in latitude $\left(\lambda_{m}\right)$ and in longitude $\left(\phi_{m}\right)$, i.e., $\exp \left[i\left(l \lambda_{m}+m \phi_{m}\right)\right]$. Using the magnetic field data from three stations, the wave numbers $m$ and $l$ are obtained by solving the following set of equations:

$$
\begin{aligned}
& \phi_{2}-\phi_{1}=\mathbf{k} \cdot\left(\mathbf{r}_{2}-\mathbf{r}_{1}\right), \\
& \phi_{3}-\phi_{1}=\mathbf{k} \cdot\left(\mathbf{r}_{3}-\mathbf{r}_{1}\right)
\end{aligned}
$$

where subscript denotes the station index, $\phi$ is the phase of the oscillation in $\mathrm{H}$ or $\mathrm{D}$ component, $\mathbf{k}=(l, m)$, and $\mathbf{r}=\left(\lambda_{m}, \phi_{m}\right)$. The positive $m$ represents an eastward propagating wave and the positive $l$ represents a northward propagating wave. Here, the filtered data recorded at the stations
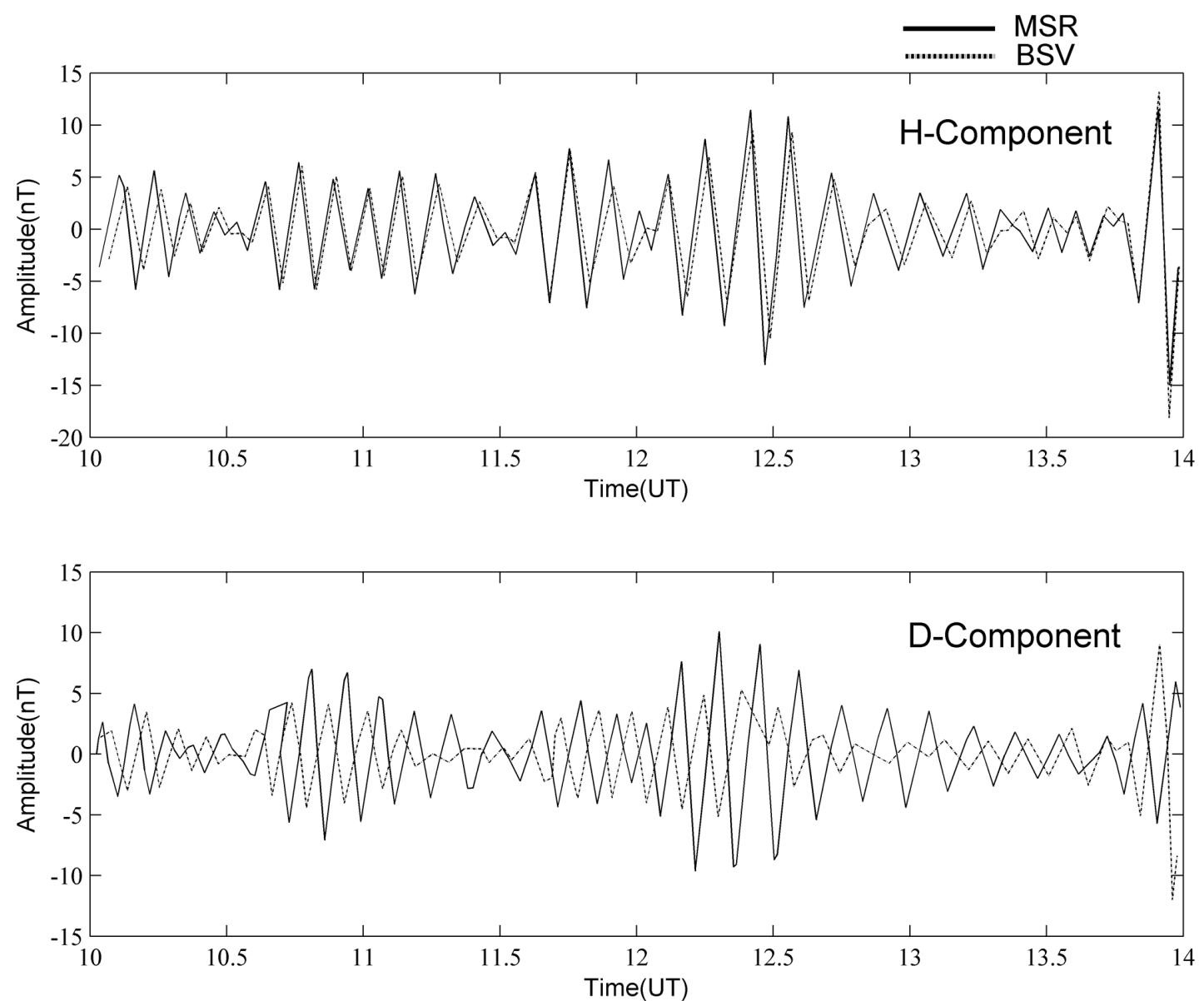

Fig. 12. Variation of the H component (top) and D component (bottom) of the geomagnetic field measured at the conjugate observatories MSR and BSV. 


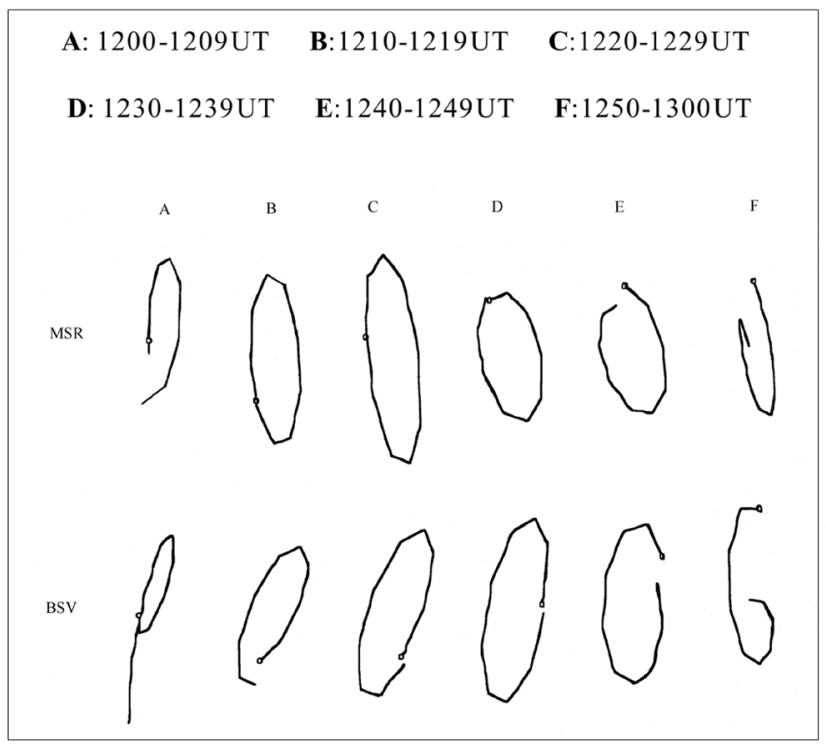

Fig. 13. Polarizations of the geomagnetic field variations at the observatories MSR and BSV during 1200 - 1300 UT ( $\bigcirc$ : starting mark).

ESK, HAD, and CLF in Region A are used for this analysis (Fig. 14). The phase difference between any two stations is obtained using the cross-correlation analysis. As shown in Table 2, the pulsations have a large $l(\sim 11)$ and a small $m(\sim 0.9)$ during 1000 - 1100 UT. In other words, the pulsations propagated northward in the latitudinal direction and westward in the longitudinal direction. All the stations were at the dawn side during this time interval. In contrast, during 1100 - 1300 UT, they were at the dusk side and the $l$ and $m$ are of the same order of magnitude. That is, the pulsations propagated eastward in the longitudinal direction and northward in the latitudinal direction.

\subsection{Correlations between Geosynchronous and Ground Observations}

The correlations between ground and satellite observations of the storm-related pulsation are described as follows. In the magnetosphere, the transverse component detected at both GOES 6 and 7 during 1000 - 1400 UT was dominant while they were on the dawn side. Meanwhile, on the ground, the corresponding latitude-independent pulsations were observed. Specifically, Region B had dominant compressional variations while Regions $\mathrm{A}$ and $\mathrm{C}$ observed dominant transverse and compressional variations. During this time span, the compressional variation observed at the ground stations and the satellites has the same frequency components (Fig. 15). In Fig. 15, the same frequency components are pointed out by the arrows. As shown in Fig. 15, station MEA in Region A had a well-correlated spectrum with GOES 6. In contrast, the stations, BFE and ESK in Region B, had a similar spectrum distribution to GOES 6 predominately at $f>2.5 \mathrm{mHz}$. During $1930-2200 \mathrm{UT}$, both the compressional and transverse components in the magnetosphere were dominant. Similarly, the corresponding latitude-independent pulsations in transverse and com-
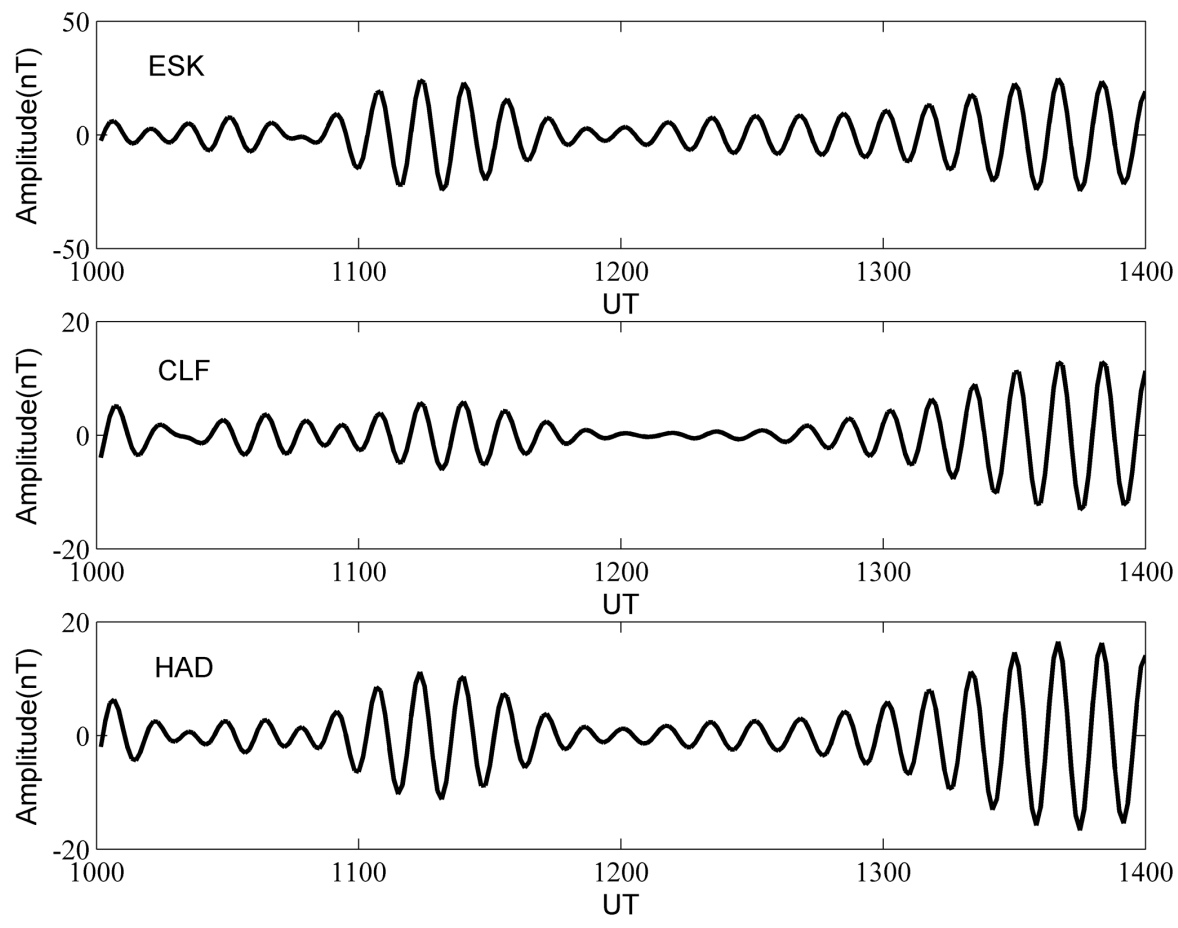

Fig. 14. Time signatures of the three stations ESK, CLF, and HAD during 1000 - 1400 UT. 
Table 2. List of the azimuthal and longitudinal wave numbers of the geomagnetic pulsations between 1000 - 1300 UT.

\begin{tabular}{ccc}
\hline Time $($ UT) & \multicolumn{1}{c}{$\boldsymbol{m}$} \\
\hline $1000-1100$ & 11.40 & -0.87 \\
$1100-1200$ & 1.19 & 2.14 \\
$1200-1300$ & 0.88 & 1.02 \\
\hline
\end{tabular}

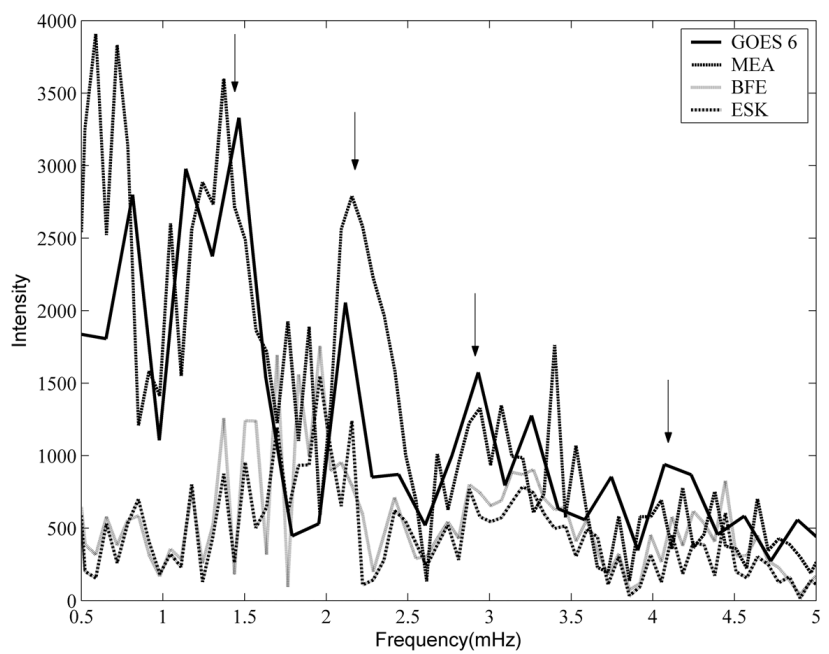

Fig. 15. Spectral correlations between the ground stations and GOES 6 during 1000 - 1400 UT.

pressional components were observed at the ground. Also, during this time span, the transverse variation observed at the ground stations (BFE, ESK, and LER in Region A) and the GOES 6 has the same frequency components pointed out by the arrows (Fig. 16), especially at $0.5<f<2 \mathrm{mHz}$.

\section{DATA INTERPRETATION AND CONCLUSION}

According to the aforementioned correlations, it is reasonable to attribute these global ULF pulsations in the magnetosphere and on the ground to the same wave event. In the magnetosphere, according to the inferred high solar wind velocity together with the strong correlation between solar wind velocity and magnetosphere wave power in the band between 150 and $600 \mathrm{~s}$ (Wolfe et al. 1987; Junginger and Baumjohann 1988), we suggest that the pulsations likely resulted from the propagation of the ULF surface waves. The interpretations are inferred from the following ground observations. First, on the ground, the similar pulsations of discrete spectrum distribution and latitude-independent frequency components were observed. The amplitude of ULF pulsations increased with an increase in geomagnetic latitude. This observation is consistent with the amplitude vari-

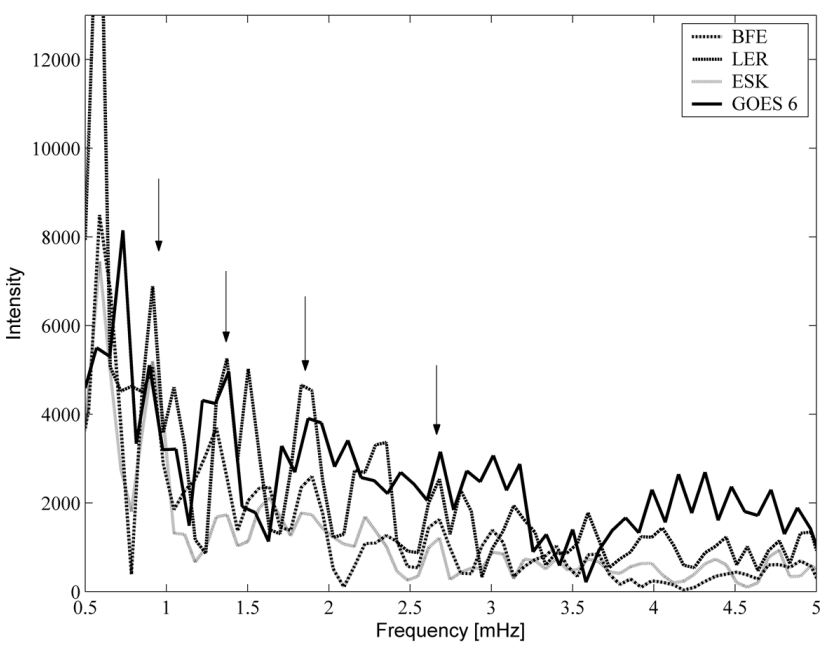

Fig. 16. Spectral correlations between the ground stations and GOES 6 during 1800 - 2200 UT.

ation caused by the surface waves. Second, the pulsations propagated toward the west at the dawn side and toward the east at the dusk side and counterclockwise and clockwise elliptical polarizations were observed at the dawn and dusk sides, respectively. Besides, the counterclockwise elliptical polarization reversed to a clockwise elliptical polarization at around geomagnetic local time and the linear polarization was observed at the reversal. These observations agree with the results predicted by a model proposed by Nagata et al. (1963) and Kokubun and Nagata (1965) for Pc 5. In their model, they describe the elliptical polarization as a result of the propagation of surface waves on the boundary of the magnetosphere.

As for the source of the ULF waves, latitude-independent frequency components often lead to explanation by the aforementioned cavity/waveguide modes; however, the strong spectral peaks with $f<1 \mathrm{mHz}$ render this explanation inconsistent for this event. Hence, the preferred source is the density oscillations present in the solar wind (Kepko et al. 2002; Kepko and Spence 2003). Unfortunately, there is no solar wind data available for further confirmation. In conclusion, the global ULF pulsations observed on 24 March 1991 were analyzed using the magnetic field data obtained from a global network. This global network provided us with not only an investigation of the characteristics of the waves in the magnetosphere and on the ground but also a development of the correlations between the geosynchronous and ground observations, which are essential to the determination of the possible mechanisms of this special event.

Acknowledgements We would like to acknowledge the value of the on-line GOES data provided by the National Oceanic and Atmospheric Administration through the World Data Center A in Boulder, Colorado, USA; the online geomagnetic data and the 1991 CD-ROM provide by 
the International Real-time Magnetic Observatory Network; and the on-line 210MM magnetic field data provided by Kyushu University in Fukuoka, Japan. This work was supported in part by the National Science Council of Taiwan, ROC, under Grant NSC 95-2111-M-008-031-AP6.

\section{REFERENCES}

Alfven, H. and C. G. Falthammar, 1963: Cosmical ElectroDynamics. $2^{\text {nd }}$ Ed., Oxford Univ. Press.

Allan, W., J. R. Manuel, and E. M. Poulter, 1991: Magnetospheric cavity modes: Some nonlinear effects. J. Geophys. Res., 96, 11461-11473.

Anderson, B. J., M. J. Engebretson, S. P. Rounds, L. J. Zanetti, and T. A. Potemra, 1990: A Statistical study of Pc 3-5 pulsations observed by the AMPTE/CCE magnetic field experiment, 1, Occurrence distributions. $J$. Geophys. Res., 95, 10495.

Barfield, J. N. and R. L. McPherron, 1972: Statistical characteristics of storm-associated Pc 5 micropulsations observed at synchronous equatorial orbit. J. Geophys. Res., 77, 4720.

Barnes, A., 1983: Hydromagnetic waves, turbulence, and collisionless processes in the interplanetary medium. In: Carovillano, R. L. and J. M. Forbes (Eds.), SolarTerrestrial Physics: Principles and Theoretical Foundations, D. Reidel Publishing Company, Dordrecht, 155-199.

Brown, W. L., L. J. Cahill, L. R. Davis, C. E. McIlwain, and C. S. Roberts, 1968: Acceleration of trapped particles during a magnetic storm on April 18, 1965. J. Geophys. Res., 73, 153.

Cahill, L. J. and J. R. Winckler, 1992: Periodic magnetopause oscillations observed with GOES satellites on March 24, 1991. J. Geophys. Res., 97, 8239-8243.

Chen, L. and A. Hasegawa, 1974: A theory of long-period magnetic pulsations, 1 . Steady state excitation of field line resonance. J. Geophys. Res., 79, 1024-1032.

Cheng, C. Z. and C. S. Lin, 1987: Eigenmode analysis of compressional waves in the magnetosphere. Geophys. Res. Lett., 14, 884-887.

Cheng, C. Z. and Q. Qian, 1994: Theory of ballooning-mirror instabilities for anisotropic pressure plasmas in the magnetosphere. J. Geophys. Res., 99, 11193-11209.

Cheng, C. Z. and S. Zaharia, 2003: Field line resonances in quiet and disturbed time three-dimensional magnetospheres. J. Geophys. Res., 108, 1001, doi: 10.1029/ 2002JA009471.

Cheng, C. Z., T. C. Chang, and W. H. Tsai, 1993: Magnetohydrodynamic theory of field line resonances in the magnetosphere. J. Geophys. Res., 98, 11339-11347.

Chisham, G. and D. Orr, 1997: A statistical study of the local time asymmetry of Pc 5 ULF wave characteristics observed at midlatitudes by SAMNET. J. Geophys. Res., 102, 24339-24350.

Ding, D. Q., R. E. Denton, M. K. Hudson, and R. L. Lysak, 1995: An MHD simulation study of the poloidal mode field line resonance in the Earth's dipole magnetosphere. J. Geophys. Res., 100, 63-77.

Dunlop, I. S., F. W. Menk, H. J. Hansen, B. J. Fraser, and R. J. Morris, 1994: A multistation study of long period geomagnetic pulsations at cusp and boundary layers latitude. J. Atmos. Terr. Phys., 56, 667-679.

Fenrich, F. R., J. C. Samson, G. sofko, and R. A. Greenwald, 1995: ULF high- and low-m field line resonances observed with the Super Dual Auroral Radar Network. J. Geophys. Res., 100, 21535.

Fujitani, S., T. Araki, K. Yumoto, K. Shiokawa, D. Orr, S. Tsunomura, Y. Yamada, H. Luhr, C. F. Lue, D. R. K. Rao, T. Kitamura, and K. Hayashi, 1993: Pc5 pulsations appeared on March 24 1991, STEPGBRSCNEWS 3, 15.

Junginger, H. and W. Baumjohann, 1988: Dayside longperiod magnetospheric pulsations: Solar wind dependence. J. Geophys. Res., 93, 877.

Keller, K. A. and R. L. Lysak, 2001: MHD simulation of magnetospheric waveguide modes. J. Geophys. Res., 106, 8447-8454.

Kepko, L. and H. E. Spence, 2003: Observations of discrete, global magnetospheric oscillations directly driven by solar wind density variations. J. Geophys. Res., 108, 1257.

Kepko, L., H. E. Spence, and H. Singer, 2002: ULF waves in the solar wind as direct drivers of magnetospheric pulsations. Geophys. Res. Lett., 29, doi: 10.1029/ 2001 GL014405.

Kivelson, M. G. and D. J. Southwood, 1991: Ionospheric traveling vortex generation by solar wind buffeting of the magnetosphere. J. Geophys. Res., 96, 1661-1667.

Kivelson, M. G., J. Etcheto, and J. G. Trotignon, 1984: Global compressional oscillations of the terrestrial magnetosphere: The evidence and a model. J. Geophys. Res., 89, 9851-9856.

Kokubun, S., 1980: Observations of Pc pulsations in the magnetosphere : Satellite-ground correlation. J. Geomagn. Geoelectr., 32, SII 17.

Kokubun, S. and T. Nagata, 1965: Geomagnetic pulsation Pc 5 in and near the auroral zones. Rept. Ionos. Space Res. Japan, 19, 158-175.

Kokubun, S., K. N. Erickson, T. A. Fritz, and R. L. McPherron, 1989: Local time asymmetry of Pc 4-5 pulsations and associated particle modulations at synchronous orbit. J. Geophys. Res., 94, 6607-6625.

Liu, J. Y., Y. N. Huang, and F. T. Berkey, 1993: The phase relationship between ULF geomagnetic pulsations and HF Doppler frequency shift oscillations on March 24, 1991. J. Geomag. Geoelectr., 45, 109-114. 
McHarg, M. G., J. V. Olson, and P. T. Newell, 1995: ULF cusp pulsations: diurnal variations and interplanetary magnetic field correlations with ground-based observations. J. Geophys. Res., 100, 19729-19742.

McPherron, R. L., 2005: Magnetic pulsations: their sources and relation to solar wind and geomagnetic activity. Surv. Geophys., 26, 545-592.

Miura, A., 1987: A simulation of Kelvin-Helmholtz instability at the magnetopause boundary. J. Geophys. Res., 92, 3195.

Nagata, T., S. Kokubun, and T. Iijima, 1963: Geomagnetically conjugate relationships of giant pulsations at Syowa Base, Antarctica and Rejkjavik, Iceland. $J$. Geophys. Res., 68, 4621-4625.

Nikutowski, B., J. Bchner, S. Klimov, S. Romanov, A. Petrukovich, and S. Savin, 1996: Long periods of the ULF wave activity in the Earth magnetotail lobes. $A d v$. Space. Res., 18, 55-58.

$\mathrm{Pu}, \mathrm{Z}$. U. and M. G. Kivelson, 1983: Kelvin-Helmholtz instability at the magnetopause: Solution for compressible plasmas. J. Geophys. Res., 88, 841.

Radoski, H. R., 1971: A note on the problem of hydromagnetic resonances in the magnetosphere. Planet. Space Sci., 19, 1012.

Rankin, R., P. Frycz, V. T. Tikhonchuk, and J. C. Samson, 1995: Ponderomotive saturation of magnetospheric field line resonances. Geophys. Res. Lett., 22, 1741-1744.

Reddy, C. A., S. Ravindran, K. S. Viswanathan, B. V. Krishna Murthy, D. R. K. Rao, and T. Araki, 1994: Observations of Pc 5 micropulsation-related electric field oscillations in the equatorial ionosphere. Ann. Geophys., 12, 565-573.

Ruohoniemi, J. M., R. A. Greenwald, K. B. Baker, and J. C. Samson, 1991: HF radar observations of Pc 5 field line resonances in the midnight early morning MLT sector. J. Geophys. Res., 96, 15697-15710.

Russell, C. T., 1985: Planetary bow shock in Collisionless Shocks in the Heliosphere: Reviews of Current Research. In: Tsurutani, B. T. and R. G. Stone (Eds.), American Geophysical Union, Washington DC, 109130.

Saka, O., M. Itonaga, and T. Kitamura, 1982: Ionospheric control of polarization of low-latitude geomagnetic micropulsations at sunrise. J. Atmos. Terr. Phys., 44, 703-712.

Samson, J. C., R. A. Greenwald, J. M. Ruohoniemi, T. J. Hughes, and D. D. Wallis, 1991: Magnetometer and radar observations of magnetohydrodynamic cavity modes in the Earth's magnetosphere. Can.J. Phys., 69, 929-937.

Samson, J. C., B. G. Harrold, J. M. Ruohoniemi, R. A. Greenwald, and A. D. M. Walker, 1992: Field line resonances associated with MHD waveguides in the magnetosphere. Geophys. Res. Lett., 19, 441-444.

Schott, J. J., N. G. Kleimenova, J. Bitterly, and O. V. Kozyreva, 1998: The strong Pc 5 geomagnetic pulsations in the initial phase of the great magnetic storm of March 24, 1991. Earth Planets Space, 50, 101-106.

Shea, M. A. and D. F. Smart, 1993: March 1991 solar-terrestrial phenomena and related technological consequences. In: Proceedings of 23rd International Comsic Ray Conference, Calgary, Canada.

Southwood, D. J., 1968: The hydromagnetic stability of the magnetospheric boundary. Planet. Space Sci., 16, 587-605.

Southwood, D. J., 1974: Some features of field line resonances in the magnetosphere. Planet. Space Sci., 22, 483.

Southwood, D. J. and W. J. Hughes, 1983: Theory of hydromagnetic waves in the magnetosphere. Space Sci. Rev., 35, 301-366.

Southwood, D. J. and M. G. Kivelson, 1991: Ionospheric traveling vortex generation by solar wind buffeting of the magnetosphere. J. Geophys. Res., 91, 1661.

Spreiter, J. R. and S. S. Stahara, 1985: Magnetohydrodynamic and gasdynamic theories for planetary bow waves. In: Tsurutani, B. T. and R. G. Stone (Eds.), Collisionless Shocks in the Heliosphere: Reviews of Current Research, American Geophysical Union, Washington DC, 85-107.

Takahashi, K. and R. L. McPherron, 1982: Harmonic structure of Pc 3-4 pulsations. J. Geophys. Res., 87, 150416.

Takahashi, K., R. E. Lopez, T. A. Potemra, L. J. Zanetti, R. W. McEntire, A. T. Y. Lui, S. M. Krimigis, and M. J. Engebretson, 1986: AMPTE/CCE observations of a compressional Pc 5 waves in the postmidnight sector. EOS Trans. AGU, 67, SM52B-08, 1182.

Takahashi, K., R. E. Lopez, T. A. Potemra, L. J. Zanetti, R. W. McEntire, A. T. Y. Lui, and S. M. Krimigis, 1987: An eastward-propagating compressional Pc 5 wave observed by the AMPTE/CCE spacecraft. Internat. Union of Geodesy and Geophys. (IUGG), XIX General Assembly, Vancouver, Canada, GA3.6-P18, 602, August $9-22$.

Takahashi, K., C. Z. Cheng, R. W. McEntire, and L. M. Kistler, 1990: Observation and theory of Pc 5 waves with harmonically related transverse and compressional components. J. Geophys. Res., 95, 977-989.

Tonegawa, Y. and N. Sato, 1987: Conjugate area study of giant geomagnetic pulsations, paper presented at Chapman Conference on Plasma Waves and Instabilities in Magnetosphere and at Comets. AGU, Sendai/Mt. Zao, Japan.

Trivedi, N. B., B. R. Arora, A. L. Padilha, J. M. Da Costa, S. L. Dutra, F. H. Chamalaun, and A. Rigoti, 1997: Global Pc 5 geomagnetic pulsations of March 24, 1991, as 
observed along the American sector. Geophys. Res. Lett., 24, 1683-1686.

Walker, A. D. M., 1998: Excitation of magnetohydrodynamic cavities in the magnetosphere. J. Atmos. Sol.Terr. Phys., 60, 1279-1293.

Walker, A. D. M., and R. A. Greenwald, 1980: Pulsation structure in the ionosphere derived from auroral radar data. J. Geomagn. Geoelectr., 32, 111-127.

Walker, A. D. M., J. M. Ruohononiemi, K. B. Baker, R. A. Greenwald, and J. C. Samson, 1992: Spatial and temporal behavior of ULF pulsations observed by Goose bay HF radar. J. Geophys. Res., 97, 12187-12202.

Waters, C. L., B. G. Harrold, F. W. Menk, J. C. Samson, and B. J. Fraser, 2000: Field line resonances and wave- guide modes at low latitudes. 2. A model. J. Geophys. Res., 105, 7763-7774.

Westphal, K. O. and J. A. Jacobs, 1962: Oscillations of the Earth's outer atmosphere and micropulsations. Geophys. J., 6, 360-376.

Wolfe, A., E. Kamen, L. J. Lanzerotti, C. G. Maclennan, J. F. Bamber, and D. Venkatesan, 1987: ULF geomagnetic power at cusp latitudes in response to upstream solar wind conditions. J. Geophys. Res., 92, 168.

Yumoto, K., Y. Tanaka, T. Oguti, K. Shiokawa, and Y. Yoshimura, 1992: Globally Coordinated Magnetic Observations along $210^{\circ}$ Magnetic Meridian During STEP Period: 1. Preliminary Results of Low-Latitude Pc 3's. J. Geomag. Geoelectr., 44, 261. 